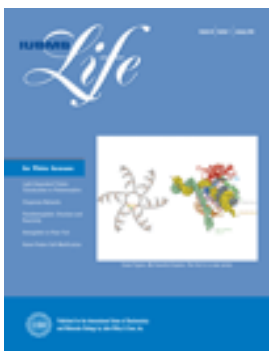

\title{
Regulation of GATA1 levels in erythropoiesis
}

\begin{tabular}{|r|l|}
\hline Journal: & IUBMB Life \\
\hline Manuscript ID & TBMB-19-0671-WJW.R1 \\
\hline Wiley - Manuscript type: & Special Issue \\
\hline Date Submitted by the & 09-Oct-2019 \\
\hline Complete List of Authors: & $\begin{array}{l}\text { Gutierrez, Laura; Instituto de Investigación Sanitaria del Principado de } \\
\text { Asturias; Universidad de Oviedo, Department of Medicine } \\
\text { Caballero, Noemi; Instituto de Investigación Sanitaria del Principado de } \\
\text { Asturias } \\
\text { Fernández-Calleja, Luis ; Instituto de Investigación Sanitaria del } \\
\text { Principado de Asturias } \\
\text { Karkoulia, Elena; IMBB } \\
\text { Strouboulis, John; King's College London, School of Cancer and } \\
\text { Pharmaceutical Sciences }\end{array}$ \\
\hline Keywords: & $\begin{array}{l}\text { transcription factors, transcriptional regulation, erythrocytes, protein } \\
\text { function }\end{array}$ \\
\hline
\end{tabular}

\section{SCHOLARONE ${ }^{\text {M }}$ \\ Manuscripts}




\title{
Regulation of GATA1 levels in erythropoiesis
}

\author{
Laura Gutiérrez ${ }^{1,2}{ }^{*}$, Noemí Caballero ${ }^{1}$, Luis Fernández-Calleja ${ }^{1}$, Elena Karkoulia ${ }^{3}$, John \\ Strouboulis ${ }^{*}$ * \\ 1 Platelet Research Lab, Instituto de Investigación Sanitaria del Principado de Asturias \\ (ISPA), Oviedo, Spain \\ 2 Dept. of Medicine, Universidad de Oviedo, Spain \\ 3 Institute of Molecular Biology and Biotechnology, Foundation of Research \& \\ Technology Hellas, Heraklion, Crete, Greece \\ 4 Cancer Comprehensive Center, School of Cancer and Pharmaceutical Sciences, \\ King's College London, United Kingdom \\ *Corresponding authors: gutierrezglaura@uniovi.es, john.strouboulis@kcl.ac.uk
}




\begin{abstract}
GATA1 is considered as the "master" transcription factor in erythropoiesis. It regulates at the transcriptional level all aspects of erythroid maturation and function, as revealed by gene knockout studies in mice and by genome-wide occupancies in erythroid cells. The GATA1 protein contains two zinc finger domains and an $\mathrm{N}$-terminal activation domain. GATA1 translation results in the production of the full-length protein and of a shorter variant (GATA1s) lacking the $\mathrm{N}$-terminal activation domain, which is functionally deficient in supporting erythropoiesis. GATA1 protein abundance is highly regulated in erythroid cells at different levels, including transcription, mRNA translation, posttranslational modifications and protein degradation, in a differentiation-stage specific manner. Maintaining high GATA1 protein levels is essential in the early stages of erythroid maturation, whereas downregulating GATA1 protein levels is a necessary step in terminal erythroid differentiation. The importance of maintaining proper GATA1 protein homeostasis in erythropoiesis is demonstrated by the fact that both GATA1 loss and its overexpression, result in lethal anemia. Importantly, alterations in any of those GATA1 regulatory checkpoints has been recognized as an important cause of hematological disorders such as dyserythropoiesis (with or without thrombocytopenia), $\beta$-thalassemia, Diamond Blackfan anemia, myelodysplasia or leukemia. In this review, we provide an overview of the multi-level regulation of GATA1 protein homeostasis in erythropoiesis and of its deregulation in hematological disease.
\end{abstract}




\section{Introduction}

Cell lineage specification and differentiation is a complex process that must be tightly regulated through cell-type specific transcriptional programs. These programs are regulated by master transcription factors which play essential roles in any given cell lineage to successfully commit and differentiate with the appropriate temporal and spatial coordinates and at the exact demanded rate, thus assuring homeostatic balance in the organismal tissue composition [1]. Hematopoiesis has long served as an excellent model system for studying the molecular principles governing transcription factor functions in regulating cell lineage commitment and differentiation. The diversity of mature blood cells derives from a common progenitor, the hematopoietic stem cell (HSC), which undergoes a series of commitment and differentiation steps in response to specific stimuli in specialized tissue microenvironments (e.g. bone marrow, thymus etc.), to generate not only the circulating blood cells (white blood cells, red blood cells and platelets), but also the immune and non-immune organ resident immune cells [2-4]. Amongst the circulating blood cells, the highly specialized, oxygen-carrying, enucleated erythroid (red blood) cells must be produced daily at high rates, according to a very specialized and well characterized cell differentiation program, which includes progressive size reduction, cell cycle arrest, massive synthesis of globin chains and enucleation [5-7]. In this respect, GATA1 has been acknowledged as the master transcriptional regulator of erythropoiesis, controlling all aspects of differentiation, survival and cell cycle arrest [8, 9]. Maintaining GATA1 protein homeostasis has been shown to be a highly regulated process in erythropoiesis, with deregulation being a major factor in ineffective erythropoiesis or leukemic transformation in hematological disease. In this review we comprehensively discuss GATA1 functions in erythroid differentiation and, further, we focus on the regulation of GATA1 abundance in physiological and pathological erythropoiesis.

\section{GATA Transcription Factors}

GATA1 belongs to the GATA family of transcription factors which comprises six members: GATA1 to GATA6. The GATA family of transcription factors plays an important role in the regulation of several biological processes, such as embryonic development, cell growth, cell differentiation and tissue morphogenesis [10]. All members of the GATA family of transcription factors recognize and bind to a specific DNA motif, (A/T)GATA(A/G) (WGATAR), through two highly conserved Cys4-type zinc finger regions. This DNA consensus sequence is evolutionarily conserved in fungi, plants, invertebrates and vertebrates, such as zebrafish, Xenopus, chicken and mammals, further supporting the notion that GATA family members play important roles in the regulation of crucial cellular processes [11]. In mammals, GATA1, GATA2 and GATA3 
have important roles primarily, but not exclusively, within the hematopoietic system [12, 13] and GATA4, GATA5, and GATA6 drive the differentiation of mesoderm and endoderm derived tissues, thus regulating diverse developmental processes within the cardiac, gastrointestinal, endocrine and gonadal systems [10]. The binding of GATA transcription factors to the WGATAR sequence motif depends highly on the C-terminal zinc finger $(\mathrm{C}-\mathrm{ZnF})$, whilst the $\mathrm{N}$-terminal zinc finger $(\mathrm{N}-\mathrm{ZnF})$ domain may bind to sites containing additional canonical, non-canonical (GATC), or palindromic GATA motifs, or may strengthen binding through interaction with other surrounding DNA motifs, mainly in partnership with other transcriptional co-factors [10, 14]. GATA transcription factor tissue/lineage specificity is afforded by the transactivation domains surrounding the zinc finger domains, the homology of which is weaker amongst the members of the GATA transcription factor family [9]. The global sequence landscape at each specific locus will determine the transcriptional activity and the higher order transcription factor complexes involved in its regulation. GATA1, the founding member of the GATA family of transcription factors, was initially shown to be essential for the erythroid/megakaryocytic lineages and subsequently in eosinophils/basophils, mast cells and in dendritic cells [1519]. However, it is the study of GATA1 in erythropoiesis that has provided the most valuable insight into GATA1 functions and regulation.

\section{GATA1 functions in erythropoiesis}

GATA1 is considered the "master" transcription factor of erythropoiesis as it transcriptionally regulates all aspects of erythroid maturation and function [9]. The GATA1 protein has three main functional domains: a N-terminal activation domain $(\mathrm{N}$ TAD) and two homologous $\mathrm{ZnF}$ domains in the C-terminal half of the protein. The C-ZnF binds to DNA and the N-ZnF binds to the GATA1 main cofactor FOG-1 (Friend of GATA1) and modulates the affinity of GATA1 for binding to complex and palindromic sites in vitro. Translation of the GATA1 mRNA produces two isoforms: the full-length protein and a shorter variant (GATA1s), translated from codon 84 within the third exon. GATA1s lacks the N-TAD and results in a protein with aberrant functional properties [20, 21]. The Gata1 gene knockout in the mouse results in embryonic lethality at around day E10.5-E11.5 due to severe anemia, with Gata1-null cells undergoing apoptosis at the proerythroblastic stage [22-24]. The conditional erythroid knockout in adult mice causes aplastic anemia, revealing its essential role in both steady-state and stress erythropoiesis [25].

Genome-wide occupancy studies (ChIPseq) have confirmed that all known erythroid genes are regulated by GATA1 [26-29]. In addition, GATA1 is critical for the positive regulation of genes involved in cell cycle regulation, such as GFI1B [30], CDC6 [31, 32] 
and p21 (Cdkn1a)[33]. GATA1 also activates genes important for cell survival, such as $\mathrm{Bcl}-2(\mathrm{Bc} / 2)$ and $\mathrm{Bcl}-\mathrm{xL}(\mathrm{Bcl} / 2 / 1)$ [34, 35]. Furthermore, GATA1 has also been described as a regulator of restrictive lineage specification through the repression of myeloid genes in the erythroid lineage. Repressed targets of GATA1 include Gata2, the Myb and Myc oncogenes and PU.1 (Spi1)[36]. Another important feature of GATA1 in the erythroid lineage differentiation, is its role as a chromatin bookmark as it has been shown that GATA1 binding to certain gene loci is preserved through mitosis, assuring the immediate expression of a given set of genes after resumption of cell cycling [37].

GATA1 transcription functions in erythropoiesis are mediated by the formation of activating and repressive transcription complexes, through GATA1 interactions with a number of other transcription factors, co-factors and chromatin remodeling and modification proteins and complexes [8]. The best studied GATA1 interactions are with FOG-1 (Friend of GATA1), the SCL/TAL1/E2A/LDB1/LMO2 complex and with PU.1 (SPI1). FOG-1 interacts with GATA1 through the latter's N-ZnF in the erythroid and megakaryocytic lineages, with their interaction being essential for differentiation [38, 39]. Genetic studies in mice and the identification of disease-causing mutations in humans, confirmed the importance in vivo of the GATA1/FOG-1 interaction in erythropoiesis [40, 41]. GATA1/FOG-1 mediated repression involves interactions with the NuRD (Nucleosome Remodeling and Deacetylating) complex, which is contacted directly by FOG-1 [42, 43].

Another critical GATA1 transcription complex in erythropoiesis is the so-called pentameric complex with the SCL/TAL1/E2A/LDB1/LMO2 factors [44]. The pentameric complex binds GATA-E-box motifs comprised of a GATA consensus sequence located proximally (7-9 bp) to an E-box CANNTG consensus motif bound by SCL/TAL1 [44]. These motifs occur primarily in erythroid specific genes that become activated by the pentameric complex $[45,46]$. LMO2 serves as the bridge between SCL/TAL1 and GATA1 [44], whereas LDB1 associates with LMO2 and is capable of self-association (dimerization) through its $\mathrm{N}$-terminus domain [47]. This dimerization allows LDB1mediated long-range DNA looping to activate transcription, as occurs, for example, in the $\beta$-globin locus $[48,49]$. GATA1 has also been reported to interact in erythroid cells with other transcription factors such as KLF1, SP1 and GFI1B [50-52], as well as with chromatin remodeling factors such as ACF/WCRF [42], BRG1 [53] and pRB/E2F [54]. Lastly, GATA1 interacts with the CBP/p300 histone acetyltransferase which mediates acetylation of the GATA1 ZnFs, modulating its DNA binding properties and/or protein stability (see below) $[55,56]$. 


\section{Cis regulation of GATA1 gene expression}

GATA1 is located on the $\mathrm{X}$ chromosome in mouse and human and is comprised of 6 exons distributed over $8 \mathrm{~Kb}$ [57]. Exon I is noncoding, exon II contains the starting codon for the full length GATA1 protein and exons IV and V code for the two ZnF domains. The Gata1 gene has been largely studied in mice. It comprises two tissue-specific promoters: the distal (IT) promoter drives expression of the Gata1 gene in Sertoli cells in the testis, whereas the proximal (IE) promoter located 8kb downstream of the IT promoter and 5' of exon II, directs Gata1 expression in hematopoietic cells [58]. The transcriptional regulation of Gata1 in hematopoietic cells is coordinated by cis-regulatory regions clustered within three DNase I hypersensitive (HS) sites [59, 60]. HS1 is located between 3.9 and $2.6 \mathrm{~kb}$ upstream of IE; HS2 corresponds to the putative region of the Gata1 IE promoter and contains a double palindromic GATA site and CACCC boxes and HS3 is located in intron I. The regulated expression of Gata1 throughout hematopoiesis involves the differential contribution of these cis-regulatory elements. Thus, in the megakaryocytic lineage, Gata1 expression requires the extended (317 bp) HS1 region, whereas for erythroid expression only the first 62bp of HS1 are necessary [61, 62]. In eosinophils, Gata1 expression is independent of the HS1 region [63], although it does require the double GATA motif that is present in the HS2 region [16]. Whereas utilization of the isolated HS sites in gene expression constructs confers normal Gata1 expression in committed hematopoietic cells, physiological repression of Gata1 in the HSC compartment requires the interspaced sequences between the HS sites [64, 65].

\section{GATA1 expression in hematopoiesis}

From earlier progenitors towards the terminally mature erythroid cell, GATA1 expression levels fluctuate. Most of the studies have been performed in murine model systems, while more recent studies tackling this aspect using single-cell approaches have been performed both in mouse and human models. HSCs and common myeloid progenitors (CMP) express very low levels of Gata1 mRNA ([65] and references therein). Gata1 expression increases moderately in early erythroid progenitors and burst-forming unitserythroid (BFU-E). High GATA1 expression levels have been shown in colony-forming units-erythroid (CFU-E): at this stage Gata1 activates the expression of the erythropoietin receptor (EpoR) and, in turn, EpoR mediated signals enhance the GATA1 transcriptional program in erythroid progenitor cells, as has been shown in vitro [34, 66-68]. After this point, expression levels of Gata1 gradually decrease from the proerythroblast stage as differentiation proceeds through the basophilic, polychromatic and orthochromatic erythroblast stages [65]. In summary, GATA1 mRNA is expressed at low levels in early 
progenitors, its expression levels reach a maximum prior to the proerythroblast stage and gradually declines towards the final maturation of erythroid cells, as has been shown in mice and human model systems $[65,69,70]$. GATA1 protein levels follow this pattern, and decrease towards terminal maturation, as was shown in mouse erythroid progenitors using a hanging-drop culture method, and comparing the levels of GATA1 protein in the same number of cells amongst successive stages of differentiation [71]. Studies using intracellular flow cytometry or flow cytometry analysis of bone marrow progenitors of GATA1-reporter transgenic mice, clearly supported this notion (Figure 1 and [70]).

Recent studies at the single cell level have also provided renewed insight as to GATA1 protein expression in human erythropoiesis, from hematopoietic stem and progenitor cells (HSPCs) to terminally differentiated erythroid cells. In one study, GATA1 protein could be detected at low levels in a subset of HSPCs, gradually increasing as cells differentiate, reaching high levels in lineage committed erythroid cells [72]. Similarly, in another study, GATA1 protein was clearly detectable at the CMP stage and gradually increased with cell commitment and differentiation through the CFU-E, proerythroblast and basophilic erythroblast and orthochromatic erythroblast stages [73]. Previously, it has been shown that GATA1 protein levels decline at the very last stages of terminal erythroid differentiation $[74,75]$, in what appears to be a regulated event necessary for terminal erythroid maturation (see below).

\section{Regulation of GATA1 mRNA translation}

The translation of the GATA1 mRNA in erythroid cells gives rise to the production of two protein isoforms as a result of the utilization of two ATG start codons: one in exon II which gives rise to full length GATA1 encoding a 413 amino acid protein and a second ATG in exon III which gives rise to a shorter isoform (GATA1s $[76,77]$ ) lacking the $\mathrm{N}$ terminalmost 83 amino acids, which span a so-called transactivation domain [78]. The GATA1 mRNA has been described to have an unusual 5' UTR structure, in that it is short and predicted to have a less complex secondary structure [72, 76]. These 5 ' UTR features are generally shared by mRNAs that are associated with increased translational efficiencies and are particularly susceptible to changes in ribosomal levels, for example, in ribosomopathies [72]. Remarkably, the GATA1 5' UTR structure is unique among a number of critical hematopoietic transcription factors which, on average, have longer 5 ' UTRs with more complex predicted structures [72]. 5' UTR swap experiments between GATA1 and other hematopoietic transcription factors, such as GATA2 or RUNX1, failed 
to rescue erythroid differentiation in a functional complementation assay in the Gata1null G1E proerythroblastic cell line [72]. Furthermore, GATA1 mRNA translation appears to have a greater requirement for elF-dependent translation initiation [76]. Lastly, recent evidence showed that GATA1 mRNA translation also requires the ribonuclease inhibitor 1 (RNH1) [79]. RNH1 associates with ribosomes and enhances GATA1 mRNA translation by enabling its recruitment to the ribosomal complex [79]. Thus, the overall picture emerging is that GATA1 mRNA translation is highly regulated in erythroid cells and disruptions in these regulatory mechanisms lead to reduced GATA1 protein levels, defective erythropoiesis and, ultimately, to disease (see below). Additionally, it appears that disruption of the complex translational regulation of the GATA1 mRNA affects translation of both full length GATA1 and of GATA1s [76].

Targeted degradation of mRNA by miRNAs is acknowledged as being a crucial checkpoint for cellular processes and tumorigenesis, however, not much is known about the miRNA-mediated regulation of GATA1 mRNA. In the teleost $C$. hamatus, the 3' UTR of the GATA1 mRNA has been reported to be a target for miR-152 [80]. This interaction reduces the expression levels of GATA1 protein and, consequently, represses hematopoiesis when miR-152 is overexpressed [80].

\section{Posttranslational modifications and GATA1 protein stability}

GATA1 undergoes several posttranslational modifications (PTMs), including phosphorylation, acetylation, sumoylation and ubiquitination. Phosphorylation occurs in seven serine residues, of which six are constitutively phosphorylated, whereas S310 phosphorylation, located near the C-ZnF of GATA1, is erythroid specific [81]. GATA1 phosphorylation occurs downstream of signaling pathways in erythroid cells, the main one being Epo activation, which leads to PI3/AKT or MAPK phosphorylation of specific GATA1 serine residues $[67,81,82]$. For example, S26 is phosphorylated by MAPK upon stimulation by IL-3 and has been linked to improved cell survival caused by increased expression of $\mathrm{Bcl}-\mathrm{XL}$ anti-apoptotic gene [83]. Whereas phosphorylation has been proposed to affect GATA1 properties such as DNA binding and transcriptional activation [84], DNA bending [85] or protein interactions [86], its relevance to GATA1 in vivo functions remains unclear [87].

GATA1 has also been shown to be acetylated by the histone acetyltransferase (HAT) $\mathrm{CBP} / \mathrm{p} 300$, at evolutionarily conserved lysine residues in the carboxyl ends of its zincfinger domains (a.a.245-252 and a.a.308-316) [56, 88]. GATA1 protein acetylation is required for terminal erythroid differentiation and for GATA1 chromatin occupancy and 
transcriptional activation $[55,56,89,90]$. Acetylated GATA1 interacts with Bromodomain Protein 3 (BRD3) which stabilizes GATA1 binding to chromatin [91]. Interestingly, the combinatorial action of GATA1 phosphorylation and acetylation has been proposed to signal GATA1 degradation by the ubiquitin/proteasome protein pathway [82]. Under this scenario, the acetylated, chromatin bound, "active" fraction of GATA1 becomes phosphorylated in response to specific external signals, or as part of the erythroid differentiation program, which in turn lead to GATA1 becoming ubiquitinated and targeted for degradation [82]. Ubiquitin mediated proteasomal degradation of acetylated GATA1 in erythroid cells appears to involve the HSP27 protein chaperone, which itself is subjected to regulation via posttranslational modification [92]. This complex regulatory network has been proposed to serve as a mean of controlling GATA1 activity at the protein level, in response to specific signaling cues in erythropoiesis [82, 92]. However, the in vivo relevance of such a mechanism remains unclear since mutating the GATA1 phoshorylatable residues does not appear to have an effect in erythropoiesis in vivo [87, 93], as would have been predicted by this model. In addition, recent work identified the USP7 deubiquitylase as interacting with and stabilizing GATA1 protein levels in human erythroid cells, by preventing its proteasomal degradation through the deubiquitination of lysine 48 [94]. However, it is not presently known how the USP7 mediated GATA1 deubiquitination relates to the acetylation and phosphorylation mediated ubiquitination of GATA1 proposed by Hernandenz-Hernandez et al. [82].

GATA1 has also been shown to undergo sumoylation in erythroid cells [95-97]. Sumoylation does not appear to affect GATA1 protein levels [97], however its functional significance remains contradictory. One study reported that sumoylation inhibits GATA1 chromatin occupancy and transcriptional activation [97], whereas another study suggested the opposite, in that sumoylation appeared to enhance GATA1 chromatin occupancy, subnuclear localization and transcriptional activation of a subset of GATA1/FOG-1 dependent target genes [96]. Either way, GATA1 sumoylation appears to add yet another layer to the regulation of GATA1 activity. However, the precise crosstalk between all of GATA1's PTMs (acetylation, phosphorylation, symoylation and ubiquitination) in regulating GATA1 protein levels and activity in vivo, remains to be elucidated.

\section{Caspase mediated GATA1 protein cleavage and terminal erythroid differentiation}

GATA1 protein has also been shown to be a target for caspase-mediated cleavage in terminal erythroid differentiation in human. In a seminal study, De Maria et al. showed that immature erythroid cells expressed several death receptors which, when activated 
by addition of ligand (e.g. Fas-L) or by incubation with mature erythroblasts, could inhibit erythroid maturation through the specific cleavage of GATA1 protein by caspases [74]. These observations led to the suggestion of a homeostatic mechanism whereby accumulation of mature erythroid cells in the erythroblastic island would lead to the activation of death receptors in immature cells, leading to caspase-mediated GATA1 protein cleavage and differentiation arrest and apoptosis [74].

In a subsequent study by Ribeil et al., it was shown that caspase 3 was the predominant caspase activated in the nucleus of terminally differentiating erythroid cells which can cleave GATA1, for example, when starving erythroid precursors for Epo, resulting in cell death by apoptosis [75]. Furthermore, Ribeil et al. uncovered a mechanism that protects GATA1 from cleavage by caspase 3 activation in the nucleus during human erythroid cell maturation. Specifically, they showed that Epo mediated erythroblast survival and terminal differentiation results in the nuclear translocation of the HSP70 protein chaperone and its specific interaction with GATA1 protein, thus protecting it from cleavage by activated caspase 3 [75]. Under conditions of Epo starvation, HSP70 translocates to the nucleus and no longer protects GATA1 which now becomes cleaved by caspase 3 , thus leading to differentiation arrest and apoptosis [75]. Thus, HSP70 protects GATA1 from programmed caspase 3 activation in the Epo-dependent, early stages of erythroid cell maturation as a cell survival and differentiation protective mechanism, whereas at later stages, Epo-independent mature erythroid cells can signal death receptor and caspase activation in immature cells, leading to GATA1 cleavage and differentiation arrest as a homeostatic control mechanism. It is unclear whether this mechanism also operates in the murine system, as murine GATA1 protein does not share the caspase cleavage site with human GATA1 [74]. Interestingly, a recent study further added to the GATA1/HSP70 protective axis by showing that nuclear HSP70 and GATA1 protein levels were modulated by the p19iNK4d cyclin-dependent kinase inhibitor [98]. Specifically, it was shown that p19ink4d downregulated PEBP1 (phosphatidylethanolamine-binding protein 1), resulting in stabilized nuclear HSP70 protein levels through increased ERK phosphorylation, known to be implicated in HSP70 nuclear localization [98]. Importantly, the GATA1/HSP70 protective mechanism breaks down in hematological disorders presenting with ineffective erythropoiesis, as outlined below.

A recent study uncovered an additional caspase-mediated mechanism for regulating GATA1 protein levels in hematopoiesis [99]. Inflammasome activation in HSCs due to infection, led to caspase 1 activation and GATA1 cleavage and degradation, thus biasing 
cell fate decisions towards the myeloid lineage. Inhibition of caspase 1 in murine HSCs resulted in the upregulation of GATA1 protein and an increase in megakaryocyticerythroid (MegE) colony output at the expense of granulocyte-monocyte (GM) colonies, suggesting an evolutionarily conserved mechanism for the inflammasome regulating hematopoietic cell fate decisions by fine-tuning GATA1. In addition, the same study showed that the cleavage of GATA1 by caspase 1 was required for the final steps of hemin-induced erythroid differentiation in K562 cells, thus pointing at an additional mechanism whereby the inflammasome could regulate erythropoiesis through GATA1. Importantly, just like for caspase 3, GATA1 was indeed shown to be a substrate for cleavage by caspase 1 in vitro [99].

\section{The effects of artificially altering GATA1 protein levels}

As outlined above, GATA1 translation and protein levels are exquisitely regulated in hematopoiesis and it is now well established that tinkering with GATA1 protein levels has important functional implications and may also result in hematological disease. For example, the extremes of either a complete loss of GATA1 expression or GATA1 overexpression, result in both cases in embryonic lethal anemia [22, 100]. Another study using inducible GATA1 expression in an immortalized GATA1-null proerythroblastic cell line, demonstrated differential sensitivity of target genes to the dosage of GATA1 protein [101]. Studies using transgenic mice under- or over-expressing GATA1 have been particularly useful in investigating the effects of altering GATA1 protein levels in hematopoiesis. Specifically, two GATA1 knockdown mouse models have been generated by the Yamamoto and Orkin groups expressing GATA1 at $5 \%$ or $20 \%$ of its physiological levels, respectively $[102,103]$. The first mouse model, called GATA1.05, was generated by the insertion of a neomycin resistance cassette in the GATA1 promoter region, which resulted in GATA1 expression at $5 \%$ its physiological level [102]. Hemizygous male GATA1.05 embryos die from severe anemia between E11.5 and E12.5, suggesting that $5 \%$ GATA1 expression is not sufficient to support primitive erythropoiesis. Interestingly, using in vitro differentiated ES cells, it was shown that both GATA1.05 and GATA1-null cells resulted in reduced expression of p16 INK4A and accelerated cell cycle progression, however, $5 \%$ of GATA1 expression was sufficient to maintain expression of the anti-apoptotic $B c l-X_{L}$ gene, thus protecting the cells from apoptotic cell death normally observed with GATA1-null cells [104]. These results provide further evidence for subtle alterations in GATA1 expression levels having differential effects on the expression of GATA1 target genes.

In contrast to male mice, heterozygous GATA1.05 female mice were born at slightly 
lower than expected Mendelian frequencies and often developed perinatally varying degrees of transient anemia (due to $X$ inactivation), from which they recovered [102, 104]. However, between 3 and 6 months of age, GATA1.05 female mice frequently develop erythroleukemia, characterized by the proliferation of immature erythroid progenitors [105]. By contrast, heterozygous GATA1-null female mice do not present with erythroleukemia. The difference between the two conditions (which only differ by $5 \%$ in the expression of GATA 1 ), may lie in the observation that $5 \%$ of GATA 1 is sufficient to protect cells from apoptosis, but not from uncontrollable cell proliferation [104]. By contrast, GATA1-null cells in a heterozygous female background would be eliminated by apoptosis. Thus, additional genetic events that my occur in the proliferating GATA1.05 progenitor population can lead to leukemic transformation [105-107]. Interestingly, older GATA1.05 mice also develop CD19+ B-cell leukemia through a leukemogenic mechanism that is not yet understood, but may be related to lineage commitment skewing towards lymphoid fates by proliferating progenitors expressing low levels of GATA1 [105].

The second GATA1 knockdown mouse strain was generated by replacing an upstream enhancer region in the GATA1 gene locus with a neomycin resistance cassette [103]. In these mice, known as GATA $1^{\text {low }}$ mice, GATA1 expression levels were originally reported to be knocked down to $20 \%$ [103], although subsequent analyses have shown GATA1 mRNA reduced by as much as 100-fold in orthochromatic erythroblasts ([108] and references therein). The majority of GATA1low male mice die of anemia between embryonic stages E13.5 and E14.5. In contrast to the GATA1.05 mice, a few GATA1 low male mice are born alive but are severely anemic, but for some of them anemia resolves around 4-5 weeks of age [103]. These observations suggest that $\sim 20 \%$ GATA1 expression is insufficient to support primitive erythropoiesis but sufficient for adult erythropoiesis. Interestingly, GATA1 expression in the megakaryocytes of GATA1 low mice is completely abolished and the mice are born with severe thrombocytopenia, associated with the expansion of abnormal megakaryocytic progenitors that, at 10 months of age, develops into a myeloproliferative condition characterized by fibrosis of the bone marrow, closely resembling primary myelofibrosis $[108,109]$. GATA $1^{\text {low }}$ mice also have defects in mast cell differentiation, as evidenced by the amplification of mast cell progenitors, increased apoptotic precursors and defective differentiation of mature cells [110]. These observations provide yet more evidence for the necessity of maintaining appropriate GATA1 levels to support balanced hematopoiesis. 
GATA1 overexpression has also been shown to have dramatic effects in erythropoiesis in vivo. In particular, a mouse model was generated bearing an X-linked GATA1 transgene driven by the Locus Control Region (LCR) of the human $\beta$-globin locus (the GATA1-OX transgene), resulting in the overexpression of GATA1 beyond the proerythroblast stage, at the moment of maximum globin transcription [100]. Male embryos carrying the GATA1-OX transgene die in utero in mid gestation due to anemia, whereas heterozygous females survive to term and develop normally. From this study it was shown that GATA1 overexpression at the proerythroblast stage causes cell cycle arrest and apoptosis of erythroid progenitors beyond the proerythroblast stage. Intriguingly, in heterozygous females it was shown that GATA1-OX progenitors were able to mature at an almost normal rate [100]. The explanation for this phenomenon lies in the erythroblastic island, i.e. the histological unit where erythropoiesis takes place in the bone marrow $[111,112]$. The erythroblastic island is composed of a central macrophage surrounded by erythroid progenitors in successive stages of differentiation, emanating from the center towards the periphery of the island. It is in this periphery where mature erythroblasts will enucleate and the expelled pyrenocyte will be phagocytosed by the central macrophage [113]. In this hierarchical histological unit, erythroid cells are in contact and communicate with each other, thus providing an internal feedback mechanism measuring differentiation rate and assuring maturation and production of red blood cells in response to physiological demands at any given moment [114, 115]. Due to X-chromosome inactivation, the erythroblastic islands of heterozygous GATA1-OX females are chimeric in composition, i.e. approximately $50 \%$ of erythroid progenitors overexpress GATA1 (the $X$ chromosome carrying the GATA1-OX transgene is active), and $50 \%$ of erythroid progenitors express GATA1 at normal levels (the wildtype $X$ chromosome is active). Based on this, it was proposed that maturing erythroid cells in later stages of differentiation induce the terminal differentiation of earlier progenitors through cell-cell signaling mechanisms, which result in the downregulation of GATA1 protein levels as a necessary regulatory cadency for proper erythroid terminal maturation [100]. This provides a mechanism to ensure a smooth production of red blood cells in wild type mice. However, in the heterozygous GATA1-OX females, this results in the "rescue" of the GATA1 overexpressing cells, which are able to differentiate when in close proximity to wildtype maturing erythroid cells, which provide a signal directed towards the downregulation of GATA1 protein levels. This signal was tentatively named "REDS" (red cell differentiation signal). A follow-up study using mice with different combinations of the GATA1-OX transgene and a GATA1-knockout allele, provided further evidence for REDS signaling by wildtype maturing erythroid cells: when crossed with GATA1 knockout mice, heterozygous GATA1-OX females died in mid gestation due to anemia 
(similar to GATA1-OX males) [116]. However, to-date, the identity of the REDS receptor/ligand is not known. Regulation of GATA1 transcription at the terminal differentiation stages and recent work suggesting that REDS might act to regulate GATA1 levels through the inhibition of translation (L. Gutiérrez, manuscript in preparation), are possibilities. Overall, the REDS signal serves as another example of homeostatic regulation of erythropoiesis through GATA1 protein level regulation.

Lastly, it should be noted that artificially altering GATA1 expression levels through its enforced expression in hematopoietic progenitors, can push them to cell fates towards lineages that are normally regulated by GATA1 [117, 118]. For example, ectopic expression of GATA1 in avian myeloid progenitors [119] or in human primary myeloid progenitors [120] reprogrammed them to erythroid and megakaryocytic or eosinophilic cell fates, respectively. These studies support the notion that different thresholds of GATA1 expression levels in hematopoietic progenitors, can govern cell fate decisions towards different lineages.

\section{Downregulation of GATA1 protein levels and ineffective erythropoiesis}

Ineffective erythropoiesis (IE) or dyserythropoiesis is a pathological feature shared by a number of hematological diseases such as $\beta$ thalassemia, myelodysplastic syndromes (MDS), Diamond-Blackfan anemia (DBA), 5q-syndrome and myelofibrosis [121]. IE is characterized by the abnormal differentiation of erythroid progenitors resulting in an expanded progenitor compartment, increased destruction of abnormal erythroblasts and a paucity in the production of mature erythroid cells. Recent work has shown that the downregulation of GATA1 protein levels is a critical aspect of IE in hematological disease. Three mechanisms have been described to account for reduced GATA1 protein levels in IE: (i) inherited GATA1 mutations greatly reducing, or eliminating altogether, expression of the full length GATA1 protein [122, 123]; (ii) impaired translation of full length GATA1 [72, 76], and (iii) impaired HSP70-mediated protection of GATA1 protein from cleavage and degradation [124].

The best example of inherited GATA1 mutations in IE is that of Diamond-Blackfan Anemia (DBA). This is an inherited bone marrow failure syndrome characterized by anemia, macrocytosis, reticulopenia and selective reduction or absence of erythroid precursors (BFU-Es) in an otherwise normocellular bone marrow [125]. More than 200 heterozygous mutations in 19 ribosomal protein (RP) genes have been recorded to-date, accounting for most (approximately $70 \%$ ), but not all, of the DBA cases [126, 127]. Sankaran and colleagues were the first to identify through exome sequencing a GATA1 mutation associated with DBA [128]. This mutation was a c.220G $>C$ transversion that 
caused the skipping of exon 2, resulting in the loss of full length GATA1 protein, with the continued expression of the GATA1s isoform. Additional cases in DBA with similar GATA1 mutations have been reported [76, 129, 130], including a mutation that resulted in the loss of the first translation initiation codon responsible for the production of full length GATA1 protein, again without affecting GATA1s expression [76, 130]. These findings are significant in explaining dyserythropoiesis in these patients, as it has been shown that the GATA1s isoform cannot fully support erythropoiesis [20, 21, 131]. Furthermore, these results show that the mutations in the GATA1 gene that give rise to reduced, or absent, full length GATA1 protein, in the absence of RP gene mutations, are sufficient to cause disease. In addition, Hollanda et al. reported a family with a similar $\mathrm{G}$ $>\mathrm{C}$ transition at the boundary of exon 2 in the GATA1 gene in male members, which also resulted in the exclusive expression of GATA1s giving rise to macrocytic anemia and variable neutropenia, with no apparent thrombocytopenia [132]. The differences in disease manifestation between the two reports of the $\mathrm{G}>\mathrm{C}$ mutation in exon 2 of the GATA1 gene remain unclear, but it has been suggested that they may be due to differences in the levels of total GATA1 protein expressed [128]. Lastly, Sankaran and colleagues recently identified two patients with dyserythropoietic anemia and thrombocytopenia, due to a mutation that affects canonical splicing of the GATA1 mRNA [133]. Specifically, a single nucleotide change was identified 24 nucleotides upstream of the canonical splice site in intron 5 of the GATA1 gene. This mutation results in an increase in the use of the mutated site as an alternative splice acceptor site, with a reduction in canonical splicing. This leads to a partial intron retention event that introduces an extra 5 amino acids C-terminally to the C-terminal zinc finger of GATA1, with a concomitant reduction in the expression of wild-type GATA1 to 40\% its normal levels. Importantly, the mutant GATA1 protein was functionally inactive as it could not rescue erythroid differentiation in functional complementation assays in the GATA1-null G1E murine proerythroblastic cell line [133].

The analysis of the molecular basis of DBA, again provided important clues as to the implication of reduced GATA1 protein levels in IE in hematological disease. As outlined above, DBA is primarily associated with heterozygous mutations in a number of RP genes. It is now known that deficiencies in RPs act upstream of GATA1 in downregulating its protein translation levels, whilst mRNA levels remain unaffected [76]. In accordance with this, knocking down RPS19 expression, or that of other RP genes, led to a significant reduction in GATA1 protein levels resulting in deficient erythropoiesis, reminiscent of DBA [76]. As described above, it appears that the particular sensitivity of the GATA1 mRNA to RP levels is mediated by the particular sequence and structure of 
its 5' UTR, as it was shown that the presence of the 5' UTR is critical for GATA1 erythroid function [72]. Interestingly, mutations in the RPS14 gene were also found in patients with primary myelofibrosis and were again associated with reduced GATA1 protein levels and impaired megakaryopoiesis [134], thus linking RP gene mutations and reduced GATA1 protein levels in hematological disease affecting a hematopoietic lineage other than the erythroid lineage. Furthermore, it was recently shown that heme levels are retroactively involved in this spectrum of phenomena around ribosomal protein dependent GATA1 protein level regulation [135]. This study showed that in early erythroid progenitors, heme induces the translation of ribosomal proteins, ensuring sustained globin synthesis. However, at later stages of differentiation, heme accumulation associates with downregulation of Gata1 through an still undescribed mechanism [135].

As described above, GATA1 protein is normally protected from caspase-mediated cleavage in the early stages of erythroid differentiation, through its interaction in the nucleus with the HSP70 protein chaperone [75]. This GATA1 protective mechanism appears to break down in hematological disorders manifesting with IE, such as DBA and myelodysplastic syndromes (MDS). In DBA, it was recently shown that HSP70 protein is downregulated due to its increased ubiquitination and proteasomal degradation in RPL11- and RPL5-deficient human primary erythroid cells, but not in RPS19-deficient cells, resulting in proliferation and differentiation defects and increased apoptosis in erythroid cells, resembling DBA features [136]. A subsequent study showed a disequilibrium of globin chain and heme synthesis in RPL11- and RPL5-deficient human erythroid cells, resulting in excessive free heme which downregulated HSP70 protein [137]. The study by Doty et al. also suggests that aberrant accumulation of heme, contributes to the amplification of ribosomal protein imbalance, thus causing premature downregulation of GATA1 levels, responsible for the IE that is characteristic of DBA and MDS [135]. Hence, it is clear in that in DBA, HSP70 downregulation results in a significant drop in GATA1 protein levels due to caspase mediated cleavage, which underlies the observed erythroid maturation defects [136]. The HSP70 mediated protection of GATA1 is also disrupted in $\beta$-thalassemia, which also manifests with IE. Here, it was shown in primary human $\beta$-thalassemic erythroblasts that free $\alpha$-globin chains sequester HSP70 to the cytoplasm, resulting in significant downregulation of nuclear GATA1 protein and a blockade in terminal erythroid differentiation [138]. Lastly, myelodysplastic syndromes are clonal disorders also characterized by IE associated with defective erythroid maturation and increased apoptosis of erythroid precursors [121]. Here too, it was shown that nuclear GATA1 protein was significantly lower as a result of aberrant HSP70 localization in the cytoplasm, accounting for the blockade in erythroid differentiation in 
MDS [124]. Thus, downregulation or absence of full length GATA1 protein in erythroid precursors, either directly through mutations in the GATA1 gene itself, or indirectly through defects in GATA1 mRNA translation or the breakdown of the HSP70/GATA1 protective axis, result in defective erythropoiesis and disease. This is an addition to hematological deficiencies or malignancies affecting other hematopoietic lineages, where downregulation or loss of the full length GATA1 protein play a causative role, for example, in primary myelofibrosis affecting the megakaryocytic lineage [108] or in trisomy 21 associated transient myeloproliferative disorder (TMD), acute megakaryoblastic leukemia (AMKL) and clonal eosinophilia [139, 140].

\section{Conclusions}

The fine-tuning of GATA1 protein levels has emerged as a key mechanism for regulating erythropoiesis. High GATA1 protein levels are required in the EPO-dependent early stages of erythropoiesis in providing cell survival functions, in addition to activating the erythroid transcription program. Adequate GATA1 protein levels in the early stages of erythroid differentiation are ensured by the efficient translation of GATA1 mRNA and its protection from cleavage by activated caspase 3 through GATA1's interaction with the HSP70 protein chaperone. Subsequently, GATA1 needs to be drastically downregulated for the terminal stage of erythroid maturation to take place, in a homeostatic mechanism that balances the production of red blood cells depending on surplus or demand. GATA1 protein levels also affect cell fate decisions, as evidenced by the reprogramming of myeloid progenitors towards MegE fates by GATA1 overexpression. Furthermore, inflammasomes appear to exploit the caspase-mediated cleavage of GATA1 in HSCs in order to tip the balance towards enhanced myeloid differentiation in response to infection. Lastly, the combined action of GATA1 post translational modifications has been proposed as a mechanism to control the active, chromatin-bound fraction of GATA1 by targeting it for proteasomal degradation as a mechanism for regulating GATA1 transcriptional activity in response to signals. It has also become clear that, not only genetic mutations affecting GATA1, but also defects in the different levels of regulatory checkpoints for physiological GATA1 expression, play a key role in the physiopathology of disease hematological diseases associated with inefficient erythropoiesis. With the advent of novel, unbiased, single cell-based technologies, we stand to gain a much better understanding of GATA1 regulatory mechanisms and the cascading effects of their deregulation in vertebrate hematopoiesis and in human disease. Newly gained knowledge will help the development of novel therapies targeting the restoration of 
GATA1 regulation in treating inefficient erythropoiesis and anemia in hematological disease in man.

\section{Acknowledgments}

We apologize to the many of our colleagues whose work we were not able to cite due to space restrictions. L.G. is supported by a Ramón y Cajal Fellowship (RYC-2013-12587; Ministerio de Economía y Competitividad, Spain). E.K. is supported by a Scholarship for Strengthening Post-Doctoral Research from the Greek State Scholarships Foundation (IKY), within the framework of the Operational Program "Human Resources Development program, Education and Life-Long learning". 


\section{References}

1. Adam, R. C., Yang, H., Rockowitz, S., Larsen, S. B., Nikolova, M., Oristian, D. S., Polak, L., Kadaja, M., Asare, A., Zheng, D. \& Fuchs, E. (2015) Pioneer factors govern super-enhancer dynamics in stem cell plasticity and lineage choice, Nature. 521, 366-70.

2. Brown, G., Ceredig, R. \& Tsapogas, P. (2018) The Making of Hematopoiesis: Developmental Ancestry and Environmental Nurture, Int J Mol Sci. 19.

3. Jacobsen, S. E. W. \& Nerlov, C. (2019) Haematopoiesis in the era of advanced single-cell technologies, Nat Cell Biol. 21, 2-8.

4. Hofer, T. \& Rodewald, H. R. (2018) Differentiation-based model of hematopoietic stem cell functions and lineage pathways, Blood. 132, 1106-1113.

5. Dzierzak, E. \& Philipsen, S. (2013) Erythropoiesis: development and differentiation, Cold Spring Harb Perspect Med. 3, a011601.

6. Liang, R. \& Ghaffari, S. (2016) Advances in understanding the mechanisms of erythropoiesis in homeostasis and disease, Br J Haematol. 174, 661-73.

7. Palis, J. (2014) Primitive and definitive erythropoiesis in mammals, Front Physiol. 5, 3.

8. Kerenyi, M. A. \& Orkin, S. H. (2010) Networking erythropoiesis, J Exp Med. 207, 2537-41.

9. Ferreira, R., Ohneda, K., Yamamoto, M. \& Philipsen, S. (2005) GATA1 function, a paradigm for transcription factors in hematopoiesis, Mol Cell Biol. 25, 1215-27.

10. Tremblay, M., Sanchez-Ferras, O. \& Bouchard, M. (2018) GATA transcription factors in development and disease, Development. 145.

11. Lowry, J. A. \& Atchley, W. R. (2000) Molecular evolution of the GATA family of transcription factors: conservation within the DNA-binding domain, J Mol Evol. 50, 103-15.

12. Weiss, M. J. \& Orkin, S. H. (1995) GATA transcription factors: key regulators of hematopoiesis, Exp Hematol. 23, 99-107.

13. Katsumura, K. R., Bresnick, E. H. \& Group, G. F. M. (2017) The GATA factor revolution in hematology, Blood. 129, 2092-2102.

14. Ko, L. J. \& Engel, J. D. (1993) DNA-binding specificities of the GATA transcription factor family, Mol Cell Biol. 13, 4011-22.

15. Vyas, P., Ault, K., Jackson, C. W., Orkin, S. H. \& Shivdasani, R. A. (1999) Consequences of GATA-1 deficiency in megakaryocytes and platelets, Blood. 93, 2867-75.

16. Yu, C., Cantor, A. B., Yang, H., Browne, C., Wells, R. A., Fujiwara, Y. \& Orkin, S. H. (2002) Targeted deletion of a high-affinity GATA-binding site in the GATA-1 promoter leads to selective loss of the eosinophil lineage in vivo, $J$ Exp Med. 195, 1387-95.

17. Nei, Y., Obata-Ninomiya, K., Tsutsui, H., Ishiwata, K., Miyasaka, M., Matsumoto, K., Nakae, S., Kanuka, H., Inase, N. \& Karasuyama, H. (2013) GATA-1 regulates the generation and function of basophils, Proc Natl Acad Sci U S A. 110, 18620-5.

18. Gutierrez, L., Nikolic, T., van Dijk, T. B., Hammad, H., Vos, N., Willart, M., Grosveld, F., Philipsen, S. \& Lambrecht, B. N. (2007) Gata1 regulates dendritic-cell development and survival, Blood. 110, 1933-41.

19. Sasaki, H., Kurotaki, D. \& Tamura, T. (2016) Regulation of basophil and mast cell development by transcription factors, Allergol Int. 65, 127-134.

20. Byrska-Bishop, M., VanDorn, D., Campbell, A. E., Betensky, M., Arca, P. R., Yao, Y., Gadue, P., Costa, F. F., Nemiroff, R. L., Blobel, G. A., French, D. L., Hardison, R. C., Weiss, M. J. \& Chou, S. T. (2015) Pluripotent stem cells reveal erythroid-specific activities of the GATA1 $\mathrm{N}$-terminus, J Clin Invest. 125, 993-1005.

21. Ling, T., Birger, Y., Stankiewicz, M. J., Ben-Haim, N., Kalisky, T., Rein, A., Kugler, E., Chen, W., Fu, C., Zhang, K., Patel, H., Sikora, J. W., Goo, Y. A., Kelleher, N., Zou, L., Izraeli, S. \& Crispino, J. D. (2019) Chromatin occupancy and epigenetic analysis reveal new insights into the function of GATA1 N-terminus in erythropoiesis, Blood.

22. Pevny, L., Simon, M. C., Robertson, E., Klein, W. H., Tsai, S. F., D'Agati, V., Orkin, S. H. \& Costantini, F. (1991) Erythroid differentiation in chimaeric mice blocked by a targeted mutation in the gene for transcription factor GATA-1, Nature. 349, 257-60.

23. Pevny, L., Lin, C. S., D'Agati, V., Simon, M. C., Orkin, S. H. \& Costantini, F. (1995)

Development of hematopoietic cells lacking transcription factor GATA-1, Development. 121, $163-72$. 
24. Weiss, M. J. \& Orkin, S. H. (1995) Transcription factor GATA-1 permits survival and maturation of erythroid precursors by preventing apoptosis, Proc Natl Acad Sci U S A. 92, 96237.

25. Gutierrez, L., Tsukamoto, S., Suzuki, M., Yamamoto-Mukai, H., Yamamoto, M., Philipsen S. \& Ohneda, K. (2008) Ablation of Gata1 in adult mice results in aplastic crisis, revealing its essential role in steady-state and stress erythropoiesis, Blood. 111, 4375-85.

26. Cheng, Y., Wu, W., Kumar, S. A., Yu, D., Deng, W., Tripic, T., King, D. C., Chen, K. B., Zhang, Y., Drautz, D., Giardine, B., Schuster, S. C., Miller, W., Chiaromonte, F., Zhang, Y., Blobel, G. A., Weiss, M. J. \& Hardison, R. C. (2009) Erythroid GATA1 function revealed by genome-wide analysis of transcription factor occupancy, histone modifications, and mRNA expression, Genome Res. 19, 2172-84.

27. Fujiwara, T., O'Geen, H., Keles, S., Blahnik, K., Linnemann, A. K., Kang, Y. A., Choi, K., Farnham, P. J. \& Bresnick, E. H. (2009) Discovering hematopoietic mechanisms through genome-wide analysis of GATA factor chromatin occupancy, Mol Cell. 36, 667-81.

28. Yu, M., Riva, L., Xie, H., Schindler, Y., Moran, T. B., Cheng, Y., Yu, D., Hardison, R., Weiss, M. J., Orkin, S. H., Bernstein, B. E., Fraenkel, E. \& Cantor, A. B. (2009) Insights into GATA-1-mediated gene activation versus repression via genome-wide chromatin occupancy analysis, Mol Cell. 36, 682-95.

29. Papadopoulos, G. L., Karkoulia, E., Tsamardinos, I., Porcher, C., Ragoussis, J., Bungert, J. \& Strouboulis, J. (2013) GATA-1 genome-wide occupancy associates with distinct epigenetic profiles in mouse fetal liver erythropoiesis, Nucleic Acids Res. 41, 4938-48.

30. Huang, D. Y., Kuo, Y. Y., Lai, J. S., Suzuki, Y., Sugano, S. \& Chang, Z. F. (2004) GATA-1 and NF-Y cooperate to mediate erythroid-specific transcription of Gfi-1B gene, Nucleic Acids Res. 32, 3935-46.

31. Vilaboa, N., Bermejo, R., Martinez, P., Bornstein, R. \& Cales, C. (2004) A novel E2 boxGATA element modulates Cdc6 transcription during human cells polyploidization, Nucleic Acids Res. 32, 6454-67.

32. Fernandez-Morales, B., Pavon, L. \& Cales, C. (2012) CDC6 expression is regulated by lineage-specific transcription factor GATA1, Cell Cycle. 11, 3055-66.

33. Papetti, M., Wontakal, S. N., Stopka, T. \& Skoultchi, A. I. (2010) GATA-1 directly regulates p21 gene expression during erythroid differentiation, Cell Cycle. 9, 1972-80.

34. Gregory, T., Yu, C., Ma, A., Orkin, S. H., Blobel, G. A. \& Weiss, M. J. (1999) GATA-1 and erythropoietin cooperate to promote erythroid cell survival by regulating bcl-xL expression, Blood. 94, 87-96.

35. Tanaka, H., Matsumura, I., Nakajima, K., Daino, H., Sonoyama, J., Yoshida, H., Oritani, K., Machii, T., Yamamoto, M., Hirano, T. \& Kanakura, Y. (2000) GATA-1 blocks IL-6-induced macrophage differentiation and apoptosis through the sustained expression of cyclin D1 and bcl-2 in a murine myeloid cell line M1, Blood. 95, 1264-73.

36. Chou, S. T., Khandros, E., Bailey, L. C., Nichols, K. E., Vakoc, C. R., Yao, Y., Huang, Z., Crispino, J. D., Hardison, R. C., Blobel, G. A. \& Weiss, M. J. (2009) Graded repression of PU.1/Sfpi1 gene transcription by GATA factors regulates hematopoietic cell fate, Blood. 114, 983-94.

37. Kadauke, S., Udugama, M. I., Pawlicki, J. M., Achtman, J. C., Jain, D. P., Cheng, Y., Hardison, R. C. \& Blobel, G. A. (2012) Tissue-specific mitotic bookmarking by hematopoietic transcription factor GATA1, Cell. 150, 725-37.

38. Tsang, A. P., Visvader, J. E., Turner, C. A., Fujiwara, Y., Yu, C., Weiss, M. J., Crossley, M. \& Orkin, S. H. (1997) FOG, a multitype zinc finger protein, acts as a cofactor for transcription factor GATA-1 in erythroid and megakaryocytic differentiation, Cell. 90, 109-19.

39. Crispino, J. D., Lodish, M. B., MacKay, J. P. \& Orkin, S. H. (1999) Use of altered specificity mutants to probe a specific protein-protein interaction in differentiation: the GATA-1:FOG complex, Mol Cell. 3, 219-28.

40. Chang, A. N., Cantor, A. B., Fujiwara, Y., Lodish, M. B., Droho, S., Crispino, J. D. \& Orkin, S. H. (2002) GATA-factor dependence of the multitype zinc-finger protein FOG-1 for its essential role in megakaryopoiesis, Proc Natl Acad Sci U S A. 99, 9237-42.

41. Nichols, K. E., Crispino, J. D., Poncz, M., White, J. G., Orkin, S. H., Maris, J. M. \& Weiss, M. J. (2000) Familial dyserythropoietic anaemia and thrombocytopenia due to an inherited mutation in GATA1, Nat Genet. 24, 266-70.

42. Rodriguez, P., Bonte, E., Krijgsveld, J., Kolodziej, K. E., Guyot, B., Heck, A. J., Vyas, P., de Boer, E., Grosveld, F. \& Strouboulis, J. (2005) GATA-1 forms distinct activating and repressive complexes in erythroid cells, EMBO J. 24, 2354-66. 
43. Hong, W., Nakazawa, M., Chen, Y. Y., Kori, R., Vakoc, C. R., Rakowski, C. \& Blobel, G. A. (2005) FOG-1 recruits the NuRD repressor complex to mediate transcriptional repression by GATA-1, EMBO J. 24, 2367-78.

44. Wadman, I. A., Osada, H., Grutz, G. G., Agulnick, A. D., Westphal, H., Forster, A. \& Rabbitts, T. H. (1997) The LIM-only protein Lmo2 is a bridging molecule assembling an erythroid, DNA-binding complex which includes the TAL1, E47, GATA-1 and Ldb1/NLI proteins, EMBO J. 16, 3145-57.

45. Kassouf, M. T., Hughes, J. R., Taylor, S., McGowan, S. J., Soneji, S., Green, A. L., Vyas, P. \& Porcher, C. (2010) Genome-wide identification of TAL1's functional targets: insights into its mechanisms of action in primary erythroid cells, Genome Res. 20, 1064-83.

46. Soler, E., Andrieu-Soler, C., de Boer, E., Bryne, J. C., Thongjuea, S., Stadhouders, R., Palstra, R. J., Stevens, M., Kockx, C., van ljcken, W., Hou, J., Steinhoff, C., Rijkers, E., Lenhard, B. \& Grosveld, F. (2010) The genome-wide dynamics of the binding of Ldb1 complexes during erythroid differentiation, Genes Dev. 24, 277-89.

47. Jurata, L. W., Pfaff, S. L. \& Gill, G. N. (1998) The nuclear LIM domain interactor NLI mediates homo- and heterodimerization of LIM domain transcription factors, J Biol Chem. 273, 3152-7.

48. Love, P. E., Warzecha, C. \& Li, L. (2014) Ldb1 complexes: the new master regulators of erythroid gene transcription, Trends Genet. 30, 1-9.

49. Liu, G. \& Dean, A. (2019) Enhancer long-range contacts: The multi-adaptor protein LDB1 is the tie that binds, Biochim Biophys Acta Gene Regul Mech. 1862, 625-633.

50. Kang, Y., Kim, Y. W., Yun, J., Shin, J. \& Kim, A. (2015) KLF1 stabilizes GATA-1 and TAL1 occupancy in the human beta-globin locus, Biochim Biophys Acta. 1849, 282-9.

51. Merika, M. \& Orkin, S. H. (1995) Functional synergy and physical interactions of the erythroid transcription factor GATA-1 with the Kruppel family proteins Sp1 and EKLF, Mol Cell Biol. 15, 2437-47.

52. Kuo, Y. Y. \& Chang, Z. F. (2007) GATA-1 and Gfi-1B interplay to regulate Bcl-xL transcription, Mol Cell Biol. 27, 4261-72.

53. Kadam, S. \& Emerson, B. M. (2003) Transcriptional specificity of human SWI/SNF BRG1 and BRM chromatin remodeling complexes, Mol Cell. 11, 377-89.

54. Kadri, Z., Shimizu, R., Ohneda, O., Maouche-Chretien, L., Gisselbrecht, S., Yamamoto, M., Romeo, P. H., Leboulch, P. \& Chretien, S. (2009) Direct binding of pRb/E2F-2 to GATA-1 regulates maturation and terminal cell division during erythropoiesis, PLoS Biol. 7, e1000123. 55. Blobel, G. A., Nakajima, T., Eckner, R., Montminy, M. \& Orkin, S. H. (1998) CREB-binding protein cooperates with transcription factor GATA-1 and is required for erythroid differentiation, Proc Natl Acad Sci U S A. 95, 2061-6.

56. Hung, H. L., Lau, J., Kim, A. Y., Weiss, M. J. \& Blobel, G. A. (1999) CREB-Binding protein acetylates hematopoietic transcription factor GATA-1 at functionally important sites, Mol Cell Biol. 19, 3496-505.

57. Zon, L. I., Tsai, S. F., Burgess, S., Matsudaira, P., Bruns, G. A. \& Orkin, S. H. (1990) The major human erythroid DNA-binding protein (GF-1): primary sequence and localization of the gene to the X chromosome, Proc Natl Acad Sci U S A. 87, 668-72.

58. Shimizu, R. \& Yamamoto, M. (2005) Gene expression regulation and domain function of hematopoietic GATA factors, Semin Cell Dev Biol. 16, 129-36.

59. McDevitt, M. A., Fujiwara, Y., Shivdasani, R. A. \& Orkin, S. H. (1997) An upstream, DNase I hypersensitive region of the hematopoietic-expressed transcription factor GATA-1 gene confers developmental specificity in transgenic mice, Proc Natl Acad Sci U S A. 94, 7976-81.

60. Valverde-Garduno, V., Guyot, B., Anguita, E., Hamlett, I., Porcher, C. \& Vyas, P. (2004) Differences in the chromatin structure and cis-element organization of the human and mouse GATA1 loci: implications for cis-element identification, Blood. 104, 3106-16.

61. Nishimura, S., Takahashi, S., Kuroha, T., Suwabe, N., Nagasawa, T., Trainor, C. \& Yamamoto, M. (2000) A GATA box in the GATA-1 gene hematopoietic enhancer is a critical element in the network of GATA factors and sites that regulate this gene, Mol Cell Biol. 20, 71323.

62. Vyas, P., McDevitt, M. A., Cantor, A. B., Katz, S. G., Fujiwara, Y. \& Orkin, S. H. (1999) Different sequence requirements for expression in erythroid and megakaryocytic cells within a regulatory element upstream of the GATA-1 gene, Development. 126, 2799-811. 63. Guyot, B., Valverde-Garduno, V., Porcher, C. \& Vyas, P. (2004) Deletion of the major GATA1 enhancer HS 1 does not affect eosinophil GATA1 expression and eosinophil differentiation, Blood. 104, 89-91. 
64. Yamamoto, M., Takahashi, S., Onodera, K., Muraosa, Y. \& Engel, J. D. (1997) Upstream and downstream of erythroid transcription factor GATA-1, Genes Cells. 2, 107-15.

65. Kobayashi, M. \& Yamamoto, M. (2007) Regulation of GATA1 gene expression, J Biochem. 142, 1-10.

66. Deindl, P., Klar, M., Drews, D., Cremer, M., Gammella, E., Gassmann, M. \& Dame, C. (2014) Mice over-expressing human erythropoietin indicate that erythropoietin enhances expression of its receptor via up-regulated Gata1 and Tal1, Haematologica. 99, e205-7. 67. Zhao, W., Kitidis, C., Fleming, M. D., Lodish, H. F. \& Ghaffari, S. (2006) Erythropoietin stimulates phosphorylation and activation of GATA-1 via the PI3-kinase/AKT signaling pathway, Blood. 107, 907-15.

68. Zon, L. I., Youssoufian, H., Mather, C., Lodish, H. F. \& Orkin, S. H. (1991) Activation of the erythropoietin receptor promoter by transcription factor GATA-1, Proc Natl Acad Sci U S A. 88, 10638-41.

69. Leonard, M., Brice, M., Engel, J. D. \& Papayannopoulou, T. (1993) Dynamics of GATA transcription factor expression during erythroid differentiation, Blood. 82, 1071-9.

70. Suzuki, N., Suwabe, N., Ohneda, O., Obara, N., Imagawa, S., Pan, X., Motohashi, H. \& Yamamoto, M. (2003) Identification and characterization of 2 types of erythroid progenitors that express GATA-1 at distinct levels, Blood. 102, 3575-83.

71. Gutierrez, L., Lindeboom, F., Ferreira, R., Drissen, R., Grosveld, F., Whyatt, D. \& Philipsen, S. (2005) A hanging drop culture method to study terminal erythroid differentiation, Exp Hematol. 33, 1083-91.

72. Khajuria, R. K., Munschauer, M., Ulirsch, J. C., Fiorini, C., Ludwig, L. S., McFarland, S. K., Abdulhay, N. J., Specht, H., Keshishian, H., Mani, D. R., Jovanovic, M., Ellis, S. R., Fulco, C. P., Engreitz, J. M., Schutz, S., Lian, J., Gripp, K. W., Weinberg, O. K., Pinkus, G. S., Gehrke, L., Regev, A., Lander, E. S., Gazda, H. T., Lee, W. Y., Panse, V. G., Carr, S. A. \& Sankaran, V. G. (2018) Ribosome Levels Selectively Regulate Translation and Lineage Commitment in Human Hematopoiesis, Cell. 173, 90-103 e19.

73. Palii, C. G., Cheng, Q., Gillespie, M. A., Shannon, P., Mazurczyk, M., Napolitani, G., Price, N. D., Ranish, J. A., Morrissey, E., Higgs, D. R. \& Brand, M. (2019) Single-Cell Proteomics Reveal that Quantitative Changes in Co-expressed Lineage-Specific Transcription Factors Determine Cell Fate, Cell Stem Cell. 24, 812-820 e5.

74. De Maria, R., Zeuner, A., Eramo, A., Domenichelli, C., Bonci, D., Grignani, F., Srinivasula, S. M., Alnemri, E. S., Testa, U. \& Peschle, C. (1999) Negative regulation of erythropoiesis by caspase-mediated cleavage of GATA-1, Nature. 401, 489-93.

75. Ribeil, J. A., Zermati, Y., Vandekerckhove, J., Cathelin, S., Kersual, J., Dussiot, M., Coulon, S., Moura, I. C., Zeuner, A., Kirkegaard-Sorensen, T., Varet, B., Solary, E., Garrido, C. \& Hermine, O. (2007) Hsp70 regulates erythropoiesis by preventing caspase-3-mediated cleavage of GATA-1, Nature. 445, 102-5.

76. Ludwig, L. S., Gazda, H. T., Eng, J. C., Eichhorn, S. W., Thiru, P., Ghazvinian, R., George, T. I., Gotlib, J. R., Beggs, A. H., Sieff, C. A., Lodish, H. F., Lander, E. S. \& Sankaran, V. G. (2014) Altered translation of GATA1 in Diamond-Blackfan anemia, Nat Med. 20, 748-53.

77. Crispino, J. D. (2005) GATA1 in normal and malignant hematopoiesis, Semin Cell Dev Biol. 16, $137-47$.

78. Martin, D. I. \& Orkin, S. H. (1990) Transcriptional activation and DNA binding by the erythroid factor GF-1/NF-E1/Eryf 1, Genes Dev. 4, 1886-98.

79. Chennupati, V., Veiga, D. F., Maslowski, K. M., Andina, N., Tardivel, A., Yu, E. C., Stilinovic, M., Simillion, C., Duchosal, M. A., Quadroni, M., Roberts, I., Sankaran, V. G., MacDonald, H. R., Fasel, N., Angelillo-Scherrer, A., Schneider, P., Hoang, T. \& Allam, R. (2018) Ribonuclease inhibitor 1 regulates erythropoiesis by controlling GATA1 translation, J Clin Invest. 128, 1597-1614.

80. Chan, J., Hu, X., Wang, C. \& Xu, Q. (2018) miRNA-152 targets GATA1 to regulate erythropoiesis in Chionodraco hamatus, Biochem Biophys Res Commun. 501, 711-717. 81. Crossley, M. \& Orkin, S. H. (1994) Phosphorylation of the erythroid transcription factor GATA-1, J Biol Chem. 269, 16589-96.

82. Hernandez-Hernandez, A., Ray, P., Litos, G., Ciro, M., Ottolenghi, S., Beug, H. \& Boyes, J. (2006) Acetylation and MAPK phosphorylation cooperate to regulate the degradation of active GATA-1, EMBO J. 25, 3264-74.

83. Yu, Y. L., Chiang, Y. J., Chen, Y. C., Papetti, M., Juo, C. G., Skoultchi, A. I. \& Yen, J. J. (2005) MAPK-mediated phosphorylation of GATA-1 promotes Bcl-XL expression and cell survival, J Biol Chem. 280, 29533-42. 
84. Partington, G. A. \& Patient, R. K. (1999) Phosphorylation of GATA-1 increases its DNAbinding affinity and is correlated with induction of human K562 erythroleukaemia cells, Nucleic Acids Res. 27, 1168-75.

85. Omichinski, J. G., Trainor, C., Evans, T., Gronenborn, A. M., Clore, G. M. \& Felsenfeld, G. (1993) A small single-"finger" peptide from the erythroid transcription factor GATA-1 binds specifically to DNA as a zinc or iron complex, Proc Natl Acad Sci U S A. 90, 1676-80. 86. Towatari, M., Ciro, M., Ottolenghi, S., Tsuzuki, S. \& Enver, T. (2004) Involvement of mitogen-activated protein kinase in the cytokine-regulated phosphorylation of transcription factor GATA-1, Hematol J. 5, 262-72.

87. Rooke, H. M. \& Orkin, S. H. (2006) Phosphorylation of Gata1 at serine residues 72, 142, and 310 is not essential for hematopoiesis in vivo, Blood. 107, 3527-30.

88. Boyes, J., Byfield, P., Nakatani, Y. \& Ogryzko, V. (1998) Regulation of activity of the transcription factor GATA-1 by acetylation, Nature. 396, 594-8.

89. Boyes, J., Omichinski, J., Clark, D., Pikaart, M. \& Felsenfeld, G. (1998) Perturbation of nucleosome structure by the erythroid transcription factor GATA-1, J Mol Biol. 279, 529-44. 90. Lamonica, J. M., Vakoc, C. R. \& Blobel, G. A. (2006) Acetylation of GATA-1 is required for chromatin occupancy, Blood. 108, 3736-8.

91. Lamonica, J. M., Deng, W., Kadauke, S., Campbell, A. E., Gamsjaeger, R., Wang, H., Cheng, Y., Billin, A. N., Hardison, R. C., Mackay, J. P. \& Blobel, G. A. (2011) Bromodomain protein Brd3 associates with acetylated GATA1 to promote its chromatin occupancy at erythroid target genes, Proc Natl Acad Sci U S A. 108, E159-68.

92. de Thonel, A., Vandekerckhove, J., Lanneau, D., Selvakumar, S., Courtois, G., Hazoume, A., Brunet, M., Maurel, S., Hammann, A., Ribeil, J. A., Zermati, Y., Gabet, A. S., Boyes, J., Solary, E., Hermine, O. \& Garrido, C. (2010) HSP27 controls GATA-1 protein level during erythroid cell differentiation, Blood. 116, 85-96.

93. Lin, K. R., Li, C. L., Yen, J. J. \& Yang-Yen, H. F. (2013) Constitutive phosphorylation of GATA-1 at serine(2)(6) attenuates the colony-forming activity of erythrocyte-committed progenitors, PLoS One. 8, e64269.

94. Liang, L., Peng, Y., Zhang, J., Zhang, Y., Roy, M., Han, X., Xiao, X., Sun, S., Liu, H., Nie, L., Kuang, Y., Zhu, Z., Deng, J., Xia, Y., Sankaran, V. G., Hillyer, C. D., Mohandas, N., Ye, M., An, X. \& Liu, J. (2019) Deubiquitylase USP7 regulates human terminal erythroid differentiation by stabilizing GATA1, Haematologica.

95. Collavin, L., Gostissa, M., Avolio, F., Secco, P., Ronchi, A., Santoro, C. \& Del Sal, G. (2004) Modification of the erythroid transcription factor GATA-1 by SUMO-1, Proc Natl Acad Sci U S A. 101, 8870-5.

96. Lee, H. Y., Johnson, K. D., Fujiwara, T., Boyer, M. E., Kim, S. I. \& Bresnick, E. H. (2009) Controlling hematopoiesis through sumoylation-dependent regulation of a GATA factor, $\mathrm{Mol}$ Cell. 36, 984-95.

97. Yu, L., Ji, W., Zhang, H., Renda, M. J., He, Y., Lin, S., Cheng, E. C., Chen, H., Krause, D. S. \& Min, W. (2010) SENP1-mediated GATA1 deSUMOylation is critical for definitive erythropoiesis, J Exp Med. 207, 1183-95.

98. Han, X., Zhang, J., Peng, Y., Peng, M., Chen, X., Chen, H., Song, J., Hu, X., Ye, M., Li, J., Sankaran, V. G., Hillyer, C. D., Mohandas, N., An, X. \& Liu, J. (2017) Unexpected role for p19INK4d in posttranscriptional regulation of GATA1 and modulation of human terminal erythropoiesis, Blood. 129, 226-237.

99. Tyrkalska, S. D., Perez-Oliva, A. B., Rodriguez-Ruiz, L., Martinez-Morcillo, F. J., AlcarazPerez, F., Martinez-Navarro, F. J., Lachaud, C., Ahmed, N., Schroeder, T., Pardo-Sanchez, I., Candel, S., Lopez-Munoz, A., Choudhuri, A., Rossmann, M. P., Zon, L. I., Cayuela, M. L., Garcia-Moreno, D. \& Mulero, V. (2019) Inflammasome Regulates Hematopoiesis through Cleavage of the Master Erythroid Transcription Factor GATA1, Immunity. 51, 50-63 e5. 100. Whyatt, D., Lindeboom, F., Karis, A., Ferreira, R., Milot, E., Hendriks, R., de Bruijn, M., Langeveld, A., Gribnau, J., Grosveld, F. \& Philipsen, S. (2000) An intrinsic but cellnonautonomous defect in GATA-1-overexpressing mouse erythroid cells, Nature. 406, 519-24. 101. Johnson, K. D., Kim, S. I. \& Bresnick, E. H. (2006) Differential sensitivities of transcription factor target genes underlie cell type-specific gene expression profiles, Proc Natl Acad Sci U S A. 103, 15939-44.

102. Takahashi, S., Onodera, K., Motohashi, H., Suwabe, N., Hayashi, N., Yanai, N., Nabesima, Y. \& Yamamoto, M. (1997) Arrest in primitive erythroid cell development caused by promoter-specific disruption of the GATA-1 gene, J Biol Chem. 272, 12611-5. 
103. McDevitt, M. A., Shivdasani, R. A., Fujiwara, Y., Yang, H. \& Orkin, S. H. (1997) A "knockdown" mutation created by cis-element gene targeting reveals the dependence of erythroid cell maturation on the level of transcription factor GATA-1, Proc Natl Acad Sci U S A. 94, 6781-5.

104. Pan, X., Ohneda, O., Ohneda, K., Lindeboom, F., Iwata, F., Shimizu, R., Nagano, M., Suwabe, N., Philipsen, S., Lim, K. C., Engel, J. D. \& Yamamoto, M. (2005) Graded levels of GATA-1 expression modulate survival, proliferation, and differentiation of erythroid progenitors, J Biol Chem. 280, 22385-94.

105. Shimizu, R., Kuroha, T., Ohneda, O., Pan, X., Ohneda, K., Takahashi, S., Philipsen, S. \& Yamamoto, M. (2004) Leukemogenesis caused by incapacitated GATA-1 function, Mol Cell Biol. 24, 10814-25.

106. Shimizu, R. \& Yamamoto, M. (2012) Contribution of GATA1 dysfunction to multi-step leukemogenesis, Cancer Sci. 103, 2039-44.

107. Shimizu, R., Engel, J. D. \& Yamamoto, M. (2008) GATA1-related leukaemias, Nat Rev Cancer. 8, 279-87.

108. Ling, T., Crispino, J. D., Zingariello, M., Martelli, F. \& Migliaccio, A. R. (2018) GATA1 insufficiencies in primary myelofibrosis and other hematopoietic disorders: consequences for therapy, Expert Rev Hematol. 11, 169-184.

109. Vannucchi, A. M., Bianchi, L., Cellai, C., Paoletti, F., Rana, R. A., Lorenzini, R., Migliaccio, G. \& Migliaccio, A. R. (2002) Development of myelofibrosis in mice genetically impaired for GATA-1 expression (GATA-1(low) mice), Blood. 100, 1123-32.

110. Migliaccio, A. R., Rana, R. A., Sanchez, M., Lorenzini, R., Centurione, L., Bianchi, L., Vannucchi, A. M., Migliaccio, G. \& Orkin, S. H. (2003) GATA-1 as a regulator of mast cell differentiation revealed by the phenotype of the GATA-1low mouse mutant, J Exp Med. 197, 281-96.

111. Socolovsky, M. (2013) Exploring the erythroblastic island, Nat Med. 19, 399-401. 112. Yeo, J. H., Lam, Y. W. \& Fraser, S. T. (2019) Cellular dynamics of mammalian red blood cell production in the erythroblastic island niche, Biophys Rev.

113. McGrath, K. E., Kingsley, P. D., Koniski, A. D., Porter, R. L., Bushnell, T. P. \& Palis, J. (2008) Enucleation of primitive erythroid cells generates a transient population of "pyrenocytes" in the mammalian fetus, Blood. 111, 2409-17.

114. Mohandas, N. \& Chasis, J. A. (2010) The erythroid niche: molecular processes occurring within erythroblastic islands, Transfus Clin Biol. 17, 110-1.

115. Chasis, J. A. \& Mohandas, N. (2008) Erythroblastic islands: niches for erythropoiesis, Blood. 112, 470-8.

116. Gutierrez, L., Lindeboom, F., Langeveld, A., Grosveld, F., Philipsen, S. \& Whyatt, D. (2004) Homotypic signalling regulates Gata1 activity in the erythroblastic island, Development. 131, 3183-93.

117. Graf, T. (2002) Differentiation plasticity of hematopoietic cells, Blood. 99, 3089-101. 118. Iwasaki, H., Mizuno, S., Wells, R. A., Cantor, A. B., Watanabe, S. \& Akashi, K. (2003) GATA-1 converts lymphoid and myelomonocytic progenitors into the megakaryocyte/erythrocyte lineages, Immunity. 19, 451-62.

119. Kulessa, H., Frampton, J. \& Graf, T. (1995) GATA-1 reprograms avian myelomonocytic cell lines into eosinophils, thromboblasts, and erythroblasts, Genes Dev. 9, 1250-62.

120. Hirasawa, R., Shimizu, R., Takahashi, S., Osawa, M., Takayanagi, S., Kato, Y., Onodera, M., Minegishi, N., Yamamoto, M., Fukao, K., Taniguchi, H., Nakauchi, H. \& Iwama, A. (2002) Essential and instructive roles of GATA factors in eosinophil development, J Exp Med. 195, 1379-86.

121. Valent, P., Busche, G., Theurl, I., Uras, I. Z., Germing, U., Stauder, R., Sotlar, K., Fureder, W., Bettelheim, P., Pfeilstocker, M., Oberbauer, R., Sperr, W. R., Geissler, K., Schwaller, J., Moriggl, R., Bene, M. C., Jager, U., Horny, H. P. \& Hermine, O. (2018) Normal and pathological erythropoiesis in adults: from gene regulation to targeted treatment concepts, Haematologica. 103, 1593-1603.

122. Barbarani, G., Fugazza, C., Strouboulis, J. \& Ronchi, A. E. (2019) The Pleiotropic Effects of GATA1 and KLF1 in Physiological Erythropoiesis and in Dyserythropoietic Disorders, Front Physiol. 10, 91.

123. Crispino, J. D. \& Horwitz, M. S. (2017) GATA factor mutations in hematologic disease, Blood. 129, 2103-2110.

124. Frisan, E., Vandekerckhove, J., de Thonel, A., Pierre-Eugene, C., Sternberg, A., Arlet, J. B., Floquet, C., Gyan, E., Kosmider, O., Dreyfus, F., Gabet, A. S., Courtois, G., Vyas, P., Ribeil, 
J. A., Zermati, Y., Lacombe, C., Mayeux, P., Solary, E., Garrido, C., Hermine, O. \& Fontenay, M. (2012) Defective nuclear localization of Hsp70 is associated with dyserythropoiesis and GATA-1 cleavage in myelodysplastic syndromes, Blood. 119, 1532-1542.

125. Ellis, S. R. \& Lipton, J. M. (2008) Diamond Blackfan anemia: a disorder of red blood cell development, Curr Top Dev Biol. 82, 217-41.

126. Ulirsch, J. C., Verboon, J. M., Kazerounian, S., Guo, M. H., Yuan, D., Ludwig, L. S., Handsaker, R. E., Abdulhay, N. J., Fiorini, C., Genovese, G., Lim, E. T., Cheng, A., Cummings, B. B., Chao, K. R., Beggs, A. H., Genetti, C. A., Sieff, C. A., Newburger, P. E., Niewiadomska, E., Matysiak, M., Vlachos, A., Lipton, J. M., Atsidaftos, E., Glader, B., Narla, A., Gleizes, P. E., O'Donohue, M. F., Montel-Lehry, N., Amor, D. J., McCarroll, S. A., O'Donnell-Luria, A. H., Gupta, N., Gabriel, S. B., MacArthur, D. G., Lander, E. S., Lek, M., Da Costa, L., Nathan, D. G., Korostelev, A. A., Do, R., Sankaran, V. G. \& Gazda, H. T. (2018) The Genetic Landscape of Diamond-Blackfan Anemia, Am J Hum Genet. 103, 930-947.

127. Boria, I., Garelli, E., Gazda, H. T., Aspesi, A., Quarello, P., Pavesi, E., Ferrante, D., Meerpohl, J. J., Kartal, M., Da Costa, L., Proust, A., Leblanc, T., Simansour, M., Dahl, N., Frojmark, A. S., Pospisilova, D., Cmejla, R., Beggs, A. H., Sheen, M. R., Landowski, M., Buros, C. M., Clinton, C. M., Dobson, L. J., Vlachos, A., Atsidaftos, E., Lipton, J. M., Ellis, S. R., Ramenghi, U. \& Dianzani, I. (2010) The ribosomal basis of Diamond-Blackfan Anemia: mutation and database update, Hum Mutat. 31, 1269-79.

128. Sankaran, V. G., Ghazvinian, R., Do, R., Thiru, P., Vergilio, J. A., Beggs, A. H., Sieff, C. A., Orkin, S. H., Nathan, D. G., Lander, E. S. \& Gazda, H. T. (2012) Exome sequencing identifies GATA1 mutations resulting in Diamond-Blackfan anemia, J Clin Invest. 122, 2439-43. 129. Klar, J., Khalfallah, A., Arzoo, P. S., Gazda, H. T. \& Dahl, N. (2014) Recurrent GATA1 mutations in Diamond-Blackfan anaemia, Br J Haematol. 166, 949-51.

130. Parrella, S., Aspesi, A., Quarello, P., Garelli, E., Pavesi, E., Carando, A., Nardi, M., Ellis, S. R., Ramenghi, U. \& Dianzani, I. (2014) Loss of GATA-1 full length as a cause of DiamondBlackfan anemia phenotype, Pediatr Blood Cancer. 61, 1319-21.

131. Chlon, T. M., McNulty, M., Goldenson, B., Rosinski, A. \& Crispino, J. D. (2015) Global transcriptome and chromatin occupancy analysis reveal the short isoform of GATA1 is deficient for erythroid specification and gene expression, Haematologica. 100, 575-84.

132. Hollanda, L. M., Lima, C. S., Cunha, A. F., Albuquerque, D. M., Vassallo, J., Ozelo, M. C., Joazeiro, P. P., Saad, S. T. \& Costa, F. F. (2006) An inherited mutation leading to production of only the short isoform of GATA-1 is associated with impaired erythropoiesis, Nat Genet. 38, 807-12.

133. Abdulhay, N. J., Fiorini, C., Verboon, J. M., Ludwig, L. S., Ulirsch, J. C., Zieger, B., Lareau, C. A., Mi, X., Roy, A., Obeng, E. A., Erlacher, M., Gupta, N., Gabriel, S. B., Ebert, B. L., Niemeyer, C. M., Khoriaty, R. N., Ancliff, P., Gazda, H. T., Wlodarski, M. W. \& Sankaran, V. G. (2019) Impaired human hematopoiesis due to a cryptic intronic GATA1 splicing mutation, $J$ Exp Med. 216, 1050-1060.

134. Gilles, L., Arslan, A. D., Marinaccio, C., Wen, Q. J., Arya, P., McNulty, M., Yang, Q., Zhao, J. C., Konstantinoff, K., Lasho, T., Pardanani, A., Stein, B., Plo, I., Sundaravel, S., Wickrema, A., Migliaccio, A., Gurbuxani, S., Vainchenker, W., Platanias, L. C., Tefferi, A. \& Crispino, J. D. (2017) Downregulation of GATA1 drives impaired hematopoiesis in primary myelofibrosis, J Clin Invest. 127, 1316-1320.

135. Doty, R. T., Yan, X., Lausted, C., Munday, A. D., Yang, Z., Yi, D., Jabbari, N., Liu, L., Keel, S. B., Tian, Q. \& Abkowitz, J. L. (2019) Single-cell analyses demonstrate that a heme-GATA1 feedback loop regulates red cell differentiation, Blood. 133, 457-469.

136. Gastou, M., Rio, S., Dussiot, M., Karboul, N., Moniz, H., Leblanc, T., Sevin, M., Gonin, P., Larghero, J., Garrido, C., Narla, A., Mohandas, N., Vainchenker, W., Hermine, O., Solary, E., Da Costa, L., French Society of, H., French Society of, I. \& Hematology (2017) The severe phenotype of Diamond-Blackfan anemia is modulated by heat shock protein 70, Blood Adv. 1, 1959-1976.

137. Rio, S., Gastou, M., Karboul, N., Derman, R., Suriyun, T., Manceau, H., Leblanc, T., El Benna, J., Schmitt, C., Azouzi, S., Larghero, J., Karim, Z., Macias-Garcia, A., Chen, J. J., Hermine, O., Courtois, G., Puy, H., Gouya, L., Mohandas, N. \& Da Costa, L. (2019) Regulation of globin-heme balance in Diamond-Blackfan anemia by HSP70/GATA1, Blood. 133, 13581370.

138. Arlet, J. B., Ribeil, J. A., Guillem, F., Negre, O., Hazoume, A., Marcion, G., Beuzard, Y., Dussiot, M., Moura, I. C., Demarest, S., de Beauchene, I. C., Belaid-Choucair, Z., Sevin, M., Maciel, T. T., Auclair, C., Leboulch, P., Chretien, S., Tchertanov, L., Baudin-Creuza, V., 
Seigneuric, R., Fontenay, M., Garrido, C., Hermine, O. \& Courtois, G. (2014) HSP70 sequestration by free alpha-globin promotes ineffective erythropoiesis in beta-thalassaemia, Nature. 514, 242-6.

139. Bhatnagar, N., Nizery, L., Tunstall, O., Vyas, P. \& Roberts, I. (2016) Transient Abnormal Myelopoiesis and AML in Down Syndrome: an Update, Curr Hematol Malig Rep. 11, 333-41. 140. Maroz, A., Stachorski, L., Emmrich, S., Reinhardt, K., Xu, J., Shao, Z., Kabler, S., Dertmann, T., Hitzler, J., Roberts, I., Vyas, P., Juban, G., Hennig, C., Hansen, G., Li, Z., Orkin, S., Reinhardt, D. \& Klusmann, J. H. (2014) GATA1s induces hyperproliferation of eosinophil precursors in Down syndrome transient leukemia, Leukemia. 28, 1259-70. 


\section{Figure Legends:}

\section{Figure 1: GATA1 protein levels during murine erythroid differentiation}

Intracellular flow cytometry analysis of GATA1 protein expression in mouse fetal and adult tissues. In brief, one million cells were stained with Ter119-PE antibody (fetal tissues) or a cocktail of KIT-PECy7/CD71-APC/Ter119-PE (adult tissues), and subsequently fixed and permeabilized using BD Cytofix/Cytoperm kit (BD Biosciences), after which they were incubated with anti-GATA1-N6 antibody (1:100) followed by antirat-FITC antibody (1:100) with a wash step after each incubation.

A) GATA1 protein levels were assessed using intracellular flow cytometry in murine fetal liver and fetal blood at E13.5. Representative data shown. In the top row, dot plots are depicted of GATA1 levels (MFI) against the Forward Scatter in fetal liver and fetal blood samples of the same mouse. In the mid row, dotplots are depicted of GATA1 levels (MFI) against Ter119 surface expression, including the Forward Scatter variable as a Heatmap Statistic colorcode in fetal liver and fetal blood samples of the same mouse. The plots on the right depict the overlay of respective fetal liver (red) and fetal blood (blue) samples on both rows. The bottom row is a composite figure, where representative pictures from cytospins of erythroid differentiating cells in vitro in hanging drop assays [71] and fetal blood nucleated and enucleated erythroid cells [116], are overlayed on the mid-row plots, as an indication of how differentiation takes place, with the remark that these cells do not correspond to prospectively isolated cells from the same samples.

B) GATA1 protein levels were assessed using intracellular flow cytometry in murine bone marrow cells. The graph represents GATA1 expression levels (GeoMFI) in successive stages of erythroid maturation based on surface marker expression, in 5 mice. The populations are from immature to mature, as follows: $\mathrm{KIT}^{+} \mathrm{CD} 71-\mathrm{Ter119}$ ( which includes other hematopoietic progenitors than erythroid), $\mathrm{KIT}^{+} \mathrm{CD} 71^{+}$Ter119-, KIT-CD71+Ter119+, KIT-CD71-Ter119+. The picture of maturing erythroid cells, is a composite of differentiating cells in hanging drop assays in vitro [71], and is used to exemplify how 
erythroid differentiation takes place, from top to bottom, following the order of gated populations in the bone marrow.

Figure 2: Model of GATA1 protein level regulation during erythroid maturation

Summary of the different mechanisms regulating GATA1 protein abundance, which lead to disease when deregulated. 
A
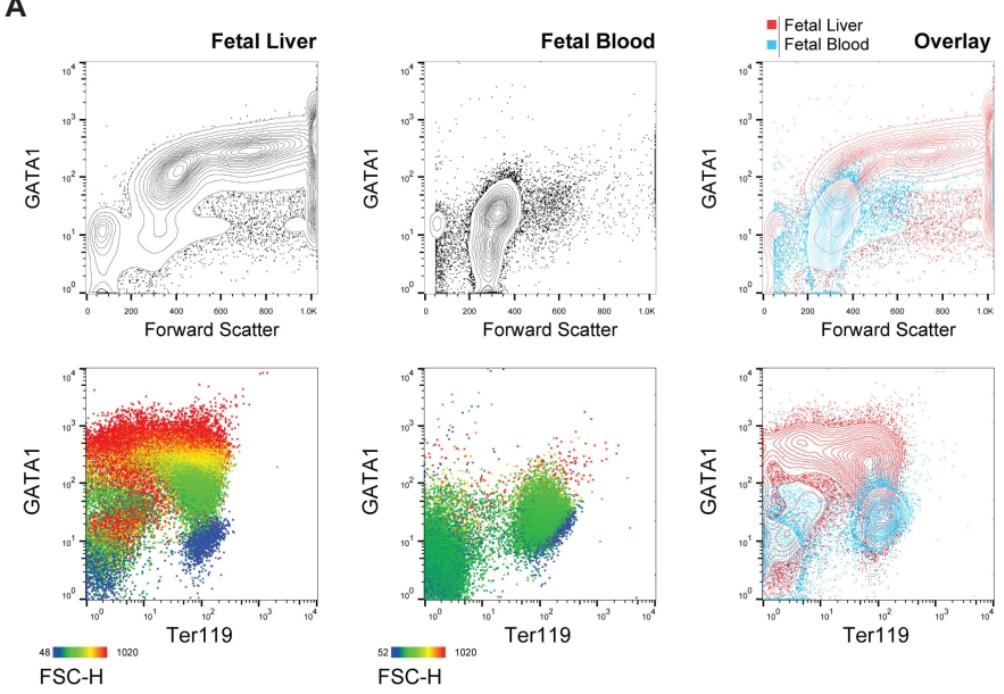
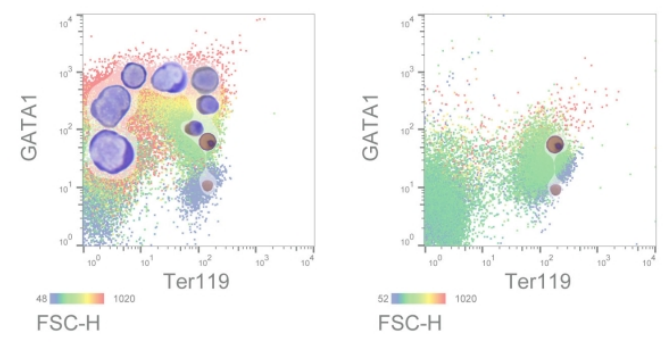

B

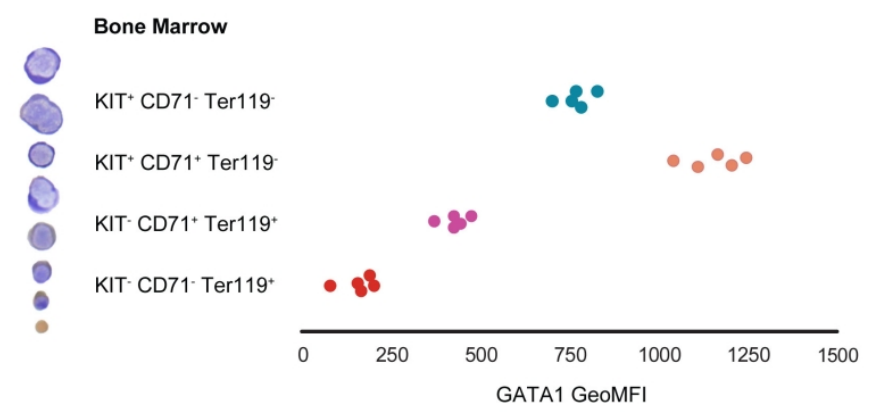

GATA1 protein levels during murine erythroid differentiation $176 \times 261 \mathrm{~mm}(300 \times 300 \mathrm{DPI})$ 


\title{
Regulation of GATA1 levels in erythropoiesis
}

\author{
Laura Gutiérrez ${ }^{1,2}{ }^{*}$, Noemí Caballero ${ }^{1}$, Luis Fernández-Calleja ${ }^{1}$, Elena Karkoulia ${ }^{3}$, John \\ Strouboulis ${ }^{*}$ * \\ 1 Platelet Research Lab, Instituto de Investigación Sanitaria del Principado de Asturias \\ (ISPA), Oviedo, Spain \\ 2 Dept. of Medicine, Universidad de Oviedo, Spain \\ 3 Institute of Molecular Biology and Biotechnology, Foundation of Research \& \\ Technology Hellas, Heraklion, Crete, Greece \\ 4 Cancer Comprehensive Center, School of Cancer and Pharmaceutical Sciences, \\ King's College London, United Kingdom \\ *Corresponding authors: gutierrezglaura@uniovi.es, john.strouboulis@kcl.ac.uk
}




\begin{abstract}
GATA1 is considered as the "master" transcription factor in erythropoiesis. It regulates at the transcriptional level all aspects of erythroid maturation and function, as revealed by gene knockout studies in mice and by genome-wide occupancies in erythroid cells. The GATA1 protein contains two zinc finger domains and an N-terminal activation domain. GATA1 translation results in the production of the full-length protein and of a shorter variant (GATA1s) lacking the $\mathrm{N}$-terminal activation domain, which is functionally deficient in supporting erythropoiesis. GATA1 protein abundance is highly regulated in erythroid cells at different levels, including transcription, mRNA translation, posttranslational modifications and protein degradation, in a differentiation-stage specific manner. Maintaining high GATA1 protein levels is essential in the early stages of erythroid maturation, whereas downregulating GATA1 protein levels is a necessary step in terminal erythroid differentiation. The importance of maintaining proper GATA1 protein homeostasis in erythropoiesis is demonstrated by the fact that both GATA1 loss and its overexpression, result in lethal anemia. Importantly, alterations in any of those GATA1 regulatory checkpoints has been recognized as an important cause of hematological disorders such as dyserythropoiesis (with or without thrombocytopenia), $\beta$-thalassemia, Diamond Blackfan anemia, myelodysplasia or leukemia. In this review, we provide an overview of the multi-level regulation of GATA1 protein homeostasis in erythropoiesis and of its deregulation in hematological disease.
\end{abstract}




\section{Introduction}

Cell lineage specification and differentiation is a complex process that must be tightly regulated through cell-type specific transcriptional programs. These programs are regulated by master transcription factors which play essential roles in any given cell lineage to successfully commit and differentiate with the appropriate temporal and spatial coordinates and at the exact demanded rate, thus assuring homeostatic balance in the organismal tissue composition [1]. Hematopoiesis has long served as an excellent model system for studying the molecular principles governing transcription factor functions in regulating cell lineage commitment and differentiation. The diversity of mature blood cells derives from a common progenitor, the hematopoietic stem cell (HSC), which undergoes a series of commitment and differentiation steps in response to specific stimuli in specialized tissue microenvironments (e.g. bone marrow, thymus etc.), to generate not only the circulating blood cells (white blood cells, red blood cells and platelets), but also the immune and non-immune organ resident immune cells [2-4]. Amongst the circulating blood cells, the highly specialized, oxygen-carrying, enucleated erythroid (red blood) cells must be produced daily at high rates, according to a very specialized and well characterized cell differentiation program, which includes progressive size reduction, cell cycle arrest, massive synthesis of globin chains and enucleation [5-7]. In this respect, GATA1 has been acknowledged as the master transcriptional regulator of erythropoiesis, controlling all aspects of differentiation, survival and cell cycle arrest [8, 9]. Maintaining GATA1 protein homeostasis has been shown to be a highly regulated process in erythropoiesis, with deregulation being a major factor in ineffective erythropoiesis or leukemic transformation in hematological disease. In this review we comprehensively discuss GATA1 functions in erythroid differentiation and, further, we focus on the regulation of GATA1 abundance in physiological and pathological erythropoiesis.

\section{GATA Transcription Factors}

GATA1 belongs to the GATA family of transcription factors which comprises six members: GATA1 to GATA6. The GATA family of transcription factors plays an important role in the regulation of several biological processes, such as embryonic development, cell growth, cell differentiation and tissue morphogenesis [10]. All members of the GATA family of transcription factors recognize and bind to a specific DNA motif, (A/T)GATA(A/G) (WGATAR), through two highly conserved Cys4-type zinc finger regions. This DNA consensus sequence is evolutionarily conserved in fungi, plants, invertebrates and vertebrates, such as zebrafish, Xenopus, chicken and mammals, further supporting the notion that GATA family members play important roles in the regulation of crucial cellular processes [11]. In mammals, GATA1, GATA2 and GATA3 
have important roles primarily, but not exclusively, within the hematopoietic system [12, 13] and GATA4, GATA5, and GATA6 drive the differentiation of mesoderm and endoderm derived tissues, thus regulating diverse developmental processes within the cardiac, gastrointestinal, endocrine and gonadal systems [10]. The binding of GATA transcription factors to the WGATAR sequence motif depends highly on the C-terminal zinc finger $(\mathrm{C}-\mathrm{ZnF})$, whilst the $\mathrm{N}$-terminal zinc finger $(\mathrm{N}-\mathrm{ZnF})$ domain may bind to sites containing additional canonical, non-canonical (GATC), or palindromic GATA motifs, or may strengthen binding through interaction with other surrounding DNA motifs, mainly in partnership with other transcriptional co-factors [10, 14]. GATA transcription factor tissue/lineage specificity is afforded by the transactivation domains surrounding the zinc finger domains, the homology of which is weaker amongst the members of the GATA transcription factor family [9]. The global sequence landscape at each specific locus will determine the transcriptional activity and the higher order transcription factor complexes involved in its regulation. GATA1, the founding member of the GATA family of transcription factors, was initially shown to be essential for the erythroid/megakaryocytic lineages and subsequently in eosinophils/basophils, mast cells and in dendritic cells [1519]. However, it is the study of GATA1 in erythropoiesis that has provided the most valuable insight into GATA1 functions and regulation.

\section{GATA1 functions in erythropoiesis}

GATA1 is considered the "master" transcription factor of erythropoiesis as it transcriptionally regulates all aspects of erythroid maturation and function [9]. The GATA1 protein has three main functional domains: a N-terminal activation domain $(\mathrm{N}$ TAD) and two homologous $\mathrm{ZnF}$ domains in the C-terminal half of the protein. The C-ZnF binds to DNA and the N-ZnF binds to the GATA1 main cofactor Friend of GATA1 (FOG-1) and modulates the affinity of GATA1 for binding to complex and palindromic sites in vitro. Translation of the GATA1 mRNA produces two isoforms: the full-length protein and a shorter variant (GATA1s), translated from codon 84 within the third exon. GATA1s lacks the N-TAD and results in a protein with aberrant functional properties [20, 21]. The Gata1 gene knockout in the mouse results in embryonic lethality at around day E10.5-E11.5 due to severe anemia, with Gata1-null cells undergoing apoptosis at the proerythroblastic stage [22-24]. The conditional erythroid knockout in adult mice causes aplastic anemia, revealing its essential role in both steady-state and stress erythropoiesis [25].

Genome-wide occupancy studies (ChIPseq) have confirmed that all known erythroid genes are regulated by GATA1 [26-29]. These have confirmed previously known GATA1 functions in regulating globin expression, heme biosynthesis and red cell membrane 
genes and further revealed new GATA1 functions in transcriptionally regulating processes essential for erythroid maturation such as autophagy and exosome suppression. For example, it was shown by Bresnick and colleagues that GATA1 activates genes involved in autophagy and in lysosomal functions, the former being an essential process for eliminating organelles through lysosomal clearance during erythroid cell maturation [30]. GATA1 was also shown to repress the exosome complex, an RNA-degrading and processing machine that promotes early erythroblast proliferation, thus allowing maturation of erythroid cells to proceed [31, 32]. In addition, GATA1 is critical for the positive regulation of genes involved in cell cycle regulation, such as GFI1B [33], CDC6 [34, 35] and p21 (Cdkn1a)[36]. GATA1 also activates genes important for cell survival, such as $\mathrm{Bcl}-2$ (Bcl2) and $\mathrm{Bcl}-\mathrm{xL}(B c / 2 / 1)[37,38]$. Furthermore, GATA1 has also been described as a regulator of restrictive lineage specification through the repression of myeloid genes in the erythroid lineage. Repressed targets of GATA1 include Gata2, the Myb and Myc oncogenes and PU.1 (Spi1)[39]. Beyond gene expression regulation, GATA1 regulates the transcription of a number of miRNAs, which serve to fine-tune the cellular gene/proteome footprint. Specifically, GATA1 regulates the expression of clusters miR-27a/24 and miR144/451, which have been shown to modulate erythropoiesis, as their deletion causes erythroid-specific defects and deregulation of a plethora of erythroid-relevant lineage specification/differentiation genes [40-42]. Another important feature of GATA1 in the erythroid lineage differentiation, is its role as a chromatin bookmark as it has been shown that GATA1 binding to certain gene loci is preserved through mitosis, assuring the immediate expression of a given set of genes after resumption of cell cycling [43].

GATA1 transcription functions in erythropoiesis are mediated by the formation of activating and repressive transcription complexes, through GATA1 interactions with a number of other transcription factors, co-factors and chromatin remodeling and modification proteins and complexes [8]. The best studied GATA1 interactions are with FOG-1, the SCL/TAL1/E2A/LDB1/LMO2 complex and with PU.1 (SPI1). FOG-1 interacts with GATA1 through the latter's N-ZnF in the erythroid and megakaryocytic lineages, with their interaction being essential for differentiation $[44,45]$. Genetic studies in mice and the identification of disease-causing mutations in humans, confirmed the importance in vivo of the GATA1/FOG-1 interaction in erythropoiesis [46, 47]. GATA1/FOG-1 mediated repression involves interactions with the NuRD (Nucleosome Remodeling and Deacetylating) complex, which is contacted directly by FOG-1 [48, 49]. Importantly, GATA1/FOG-1 interactions have a dual function in the activation of the erythroid-specific program, as well as the repression of alternative hematopoietic transcription programs, 
often supported in both cases by NuRD [48-50].

Another critical GATA1 transcription complex in erythropoiesis is the so-called pentameric complex with the SCL/TAL1/E2A/LDB1/LMO2 factors which is associated with transcriptional activation [51]. The pentameric complex binds GATA-E-box motifs comprised of a GATA consensus sequence located proximally (7-9 bp) to an E-box CANNTG consensus motif bound by SCL/TAL1 [51]. These motifs occur primarily in erythroid specific genes that become activated by the pentameric complex [52, 53]. LMO2 serves as the bridge between SCL/TAL1 and GATA1 [51], whereas LDB1 associates with LMO2 and is capable of self-association (dimerization) through its $\mathrm{N}$ terminus domain [54]. This dimerization allows LDB1-mediated long-range DNA looping to activate transcription, as occurs, for example, in the $\beta$-globin locus $[55,56]$. GATA1 and the myeloid transcription factor PU.1 have been reported to physically interact in antagonizing each other's functions by displacing other protein co-factors and/or preventing DNA binding, thus influencing cell lineage commitment decisions and activation of associated transcription programs ([57] and references therein). GATA1 also interacts in erythroid cells with other transcription factors such as KLF1, SP1 and GFI1B [58-60], as well as with chromatin remodeling factors such as ACF/WCRF [48], BRG1 [61] and pRB/E2F [62]. Lastly, GATA1 interacts with the CBP/p300 histone acetyltransferase which mediates acetylation of the GATA1 ZnFs, modulating its DNA binding properties and/or protein stability (see below) [63, 64].

\section{Cis regulation of GATA1 gene expression}

GATA 1 is located on the $X$ chromosome in mouse and human and is comprised of 6 exons distributed over $8 \mathrm{~Kb}$ [65]. Exon I is noncoding, exon II contains the starting codon for the full length GATA1 protein and exons IV and V code for the two ZnF domains. The Gata1 gene has been largely studied in mice. It comprises two tissue-specific promoters: the distal (IT) promoter drives expression of the Gata1 gene in Sertoli cells in the testis, whereas the proximal (IE) promoter located 8kb downstream of the IT promoter and 5' of exon II, directs Gata1 expression in hematopoietic cells [66]. The transcriptional regulation of Gata1 in hematopoietic cells is coordinated by cis-regulatory regions clustered within three DNase I hypersensitive (HS) sites [67, 68]. HS1 is located between 3.9 and $2.6 \mathrm{~kb}$ upstream of IE; HS2 corresponds to the putative region of the Gata1 IE promoter and contains a double palindromic GATA site and CACCC boxes and HS3 is located in intron I. The regulated expression of Gata1 throughout hematopoiesis involves the differential contribution of these cis-regulatory elements. Thus, in the megakaryocytic lineage, Gata1 expression requires the extended (317 bp) HS1 region, whereas for 
erythroid expression only the first $62 \mathrm{bp}$ of HS1 are necessary [69, 70]. In eosinophils, Gata1 expression is independent of the HS1 region [71], although it does require the double GATA motif that is present in the HS2 region [16]. Whereas utilization of the isolated HS sites in gene expression constructs confers normal Gata1 expression in committed hematopoietic cells, physiological repression of Gata1 in the HSC compartment requires the interspaced sequences between the HS sites [72, 73].

\section{GATA1 expression in hematopoiesis}

From earlier progenitors towards the terminally mature erythroid cell, GATA1 expression levels fluctuate. Most of the studies have been performed in murine model systems, while more recent studies tackling this aspect using single-cell approaches have been performed both in mouse and human models. HSCs and common myeloid progenitors (CMP) express very low levels of Gata1 mRNA ([73] and references therein). Gata1 expression increases moderately in early erythroid progenitors and burst-forming unitserythroid (BFU-E). High GATA1 expression levels have been shown in colony-forming units-erythroid (CFU-E): at this stage Gata1 activates the expression of the erythropoietin receptor (EpoR) and, in turn, EpoR mediated signals enhance the GATA1 transcriptional program in erythroid progenitor cells, as has been shown in vitro [37, 74-76]. After this point, expression levels of Gata1 gradually decrease from the proerythroblast stage as differentiation proceeds through the basophilic, polychromatic and orthochromatic erythroblast stages [73]. In summary, GATA1 mRNA is expressed at low levels in early progenitors, its expression levels reach a maximum prior to the proerythroblast stage and gradually declines towards the final maturation of erythroid cells, as has been shown in mice and human model systems $[73,77,78]$. GATA1 protein levels follow this pattern, and decrease towards terminal maturation, as was shown in mouse erythroid progenitors using a hanging-drop culture method, and comparing the levels of GATA1 protein in the same number of cells amongst successive stages of differentiation [79]. Studies using intracellular flow cytometry or flow cytometry analysis of bone marrow progenitors of GATA1-reporter transgenic mice, clearly supported this notion (Figure 1 and [78]).

Recent studies at the single cell level have also provided renewed insight as to GATA1 protein expression in human erythropoiesis, from hematopoietic stem and progenitor cells (HSPCs) to terminally differentiated erythroid cells. In one study, GATA1 protein could be detected at low levels in a subset of HSPCs, gradually increasing as cells differentiate, reaching high levels in lineage committed erythroid cells [80]. Similarly, in another study, GATA1 protein was clearly detectable at the CMP stage and gradually increased with cell commitment and differentiation through the CFU-E, proerythroblast 
and basophilic erythroblast and orthochromatic erythroblast stages [81]. Previously, it has been shown that GATA1 protein levels decline at the very last stages of terminal erythroid differentiation $[82,83]$, in what appears to be a regulated event necessary for terminal erythroid maturation (see below).

\section{Regulation of GATA1 mRNA translation}

The translation of the GATA1 mRNA in erythroid cells gives rise to the production of two protein isoforms as a result of the utilization of two ATG start codons: one in exon II which gives rise to full length GATA1 encoding a 413 amino acid protein and a second ATG in exon III which gives rise to a shorter isoform (GATA1s $[84,85]$ ) lacking the $\mathrm{N}$ terminalmost 83 amino acids, which span a so-called transactivation domain [86]. The GATA1 mRNA has been described to have an unusual 5' UTR structure, in that it is short and predicted to have a less complex secondary structure [80, 84]. These 5' UTR features are generally shared by mRNAs that are associated with increased translational efficiencies and are particularly susceptible to changes in ribosomal levels, for example, in ribosomopathies [80]. Remarkably, the GATA1 5' UTR structure is unique among a number of critical hematopoietic transcription factors which, on average, have longer 5 ' UTRs with more complex predicted structures [80]. 5' UTR swap experiments between GATA1 and other hematopoietic transcription factors, such as GATA2 or RUNX1, failed to rescue erythroid differentiation in a functional complementation assay in the Gata1null G1E proerythroblastic cell line [80]. Furthermore, GATA1 mRNA translation appears to have a greater requirement for elF-dependent translation initiation [84]. Lastly, recent evidence showed that GATA1 mRNA translation also requires the ribonuclease inhibitor 1 (RNH1) [87]. RNH1 associates with ribosomes and enhances GATA1 mRNA translation by enabling its recruitment to the ribosomal complex [87]. Thus, the overall picture emerging is that GATA1 mRNA translation is highly regulated in erythroid cells and disruptions in these regulatory mechanisms lead to reduced GATA1 protein levels, defective erythropoiesis and, ultimately, to disease (see below). Additionally, it appears that disruption of the complex translational regulation of the GATA1 mRNA affects translation of both full length GATA1 and of GATA1s [84].

Targeted degradation of mRNA by miRNAs is acknowledged as being a crucial checkpoint for cellular processes and tumorigenesis, however, not much is known about the miRNA-mediated regulation of GATA1 mRNA. In the teleost $C$. hamatus, the 3' UTR of the GATA1 mRNA has been reported to be a target for miR-152 [88]. This interaction reduces the expression levels of GATA1 protein and, consequently, represses 
hematopoiesis when miR-152 is overexpressed [88]. In mammals, regulation of GATA1 levels by microRNAs has not been validated yet, including miRNAs that have been described to modulate erythropoiesis [89-91].

\section{Posttranslational modifications and GATA1 protein stability}

GATA1 undergoes several posttranslational modifications (PTMs), including phosphorylation, acetylation, sumoylation and ubiquitination. Phosphorylation occurs in seven serine residues, of which six are constitutively phosphorylated, whereas S310 phosphorylation, located near the C-ZnF of GATA1, is erythroid specific [92]. GATA1 phosphorylation occurs downstream of signaling pathways in erythroid cells, the main one being Epo activation, which leads to PI3/AKT or MAPK phosphorylation of specific GATA1 serine residues [75, 92, 93]. For example, S26 is phosphorylated by MAPK upon stimulation by IL-3 and has been linked to improved cell survival caused by increased expression of Bcl-XL anti-apoptotic gene [94]. Whereas phosphorylation has been proposed to affect GATA1 properties such as DNA binding and transcriptional activation [95], DNA bending [96] or protein interactions [97], its relevance to GATA1 in vivo functions remains unclear [98].

GATA1 has also been shown to be acetylated by the histone acetyltransferase (HAT) $\mathrm{CBP} / \mathrm{p} 300$, at evolutionarily conserved lysine residues in the carboxyl ends of its zincfinger domains (a.a.245-252 and a.a.308-316) [64, 99]. GATA1 protein acetylation is required for terminal erythroid differentiation and for GATA1 chromatin occupancy and transcriptional activation $[63,64,100,101]$. Acetylated GATA1 interacts with Bromodomain Protein 3 (BRD3) which stabilizes GATA1 binding to chromatin [102]. Interestingly, the combinatorial action of GATA1 phosphorylation and acetylation has been proposed to signal GATA1 degradation by the ubiquitin/proteasome protein pathway [93]. Under this scenario, the acetylated, chromatin bound, "active" fraction of GATA1 becomes phosphorylated in response to specific external signals, or as part of the erythroid differentiation program, which in turn lead to GATA1 becoming ubiquitinated and targeted for degradation [93]. Ubiquitin mediated proteasomal degradation of acetylated GATA1 in erythroid cells appears to involve the HSP27 protein chaperone, which itself is subjected to regulation via posttranslational modification [103]. This complex regulatory network has been proposed to serve as a mean of controlling GATA1 activity at the protein level, in response to specific signaling cues in erythropoiesis [93, 103]. However, the in vivo relevance of such a mechanism remains unclear since mutating the GATA1 phoshorylatable residues does not appear to have an effect in erythropoiesis in vivo $[98,104]$, as would have been predicted by this model. In addition, 
recent work identified the USP7 deubiquitylase as interacting with and stabilizing GATA1 protein levels in human erythroid cells, by preventing its proteasomal degradation through the deubiquitination of lysine 48 [105]. However, it is not presently known how the USP7 mediated GATA1 deubiquitination relates to the acetylation and phosphorylation mediated ubiquitination of GATA1 proposed by Hernandez-Hernandez et al. [93].

GATA1 has also been shown to undergo sumoylation in erythroid cells [106-108]. Sumoylation does not appear to affect GATA1 protein levels [108], however its functional significance remains contradictory. One study reported that sumoylation inhibits GATA1 chromatin occupancy and transcriptional activation [108], whereas another study suggested the opposite, in that sumoylation appeared to enhance GATA1 chromatin occupancy, subnuclear localization and transcriptional activation of a subset of GATA1/FOG-1 dependent target genes [107]. Either way, GATA1 sumoylation appears to add yet another layer to the regulation of GATA1 activity. However, the precise crosstalk between all of GATA1's PTMs (acetylation, phosphorylation, sumoylation and ubiquitination) in regulating GATA1 protein levels and activity in vivo, remains to be elucidated.

\section{Caspase mediated GATA1 protein cleavage and terminal erythroid differentiation}

GATA1 protein has also been shown to be a target for caspase-mediated cleavage in terminal erythroid differentiation in human. In a seminal study, De Maria et al. showed that immature erythroid cells expressed several death receptors which, when activated by addition of ligand (e.g. Fas-L) or by incubation with mature erythroblasts, could inhibit erythroid maturation through the specific cleavage of GATA1 protein by caspases [82]. These observations led to the suggestion of a homeostatic mechanism whereby accumulation of mature erythroid cells in the erythroblastic island would lead to the activation of death receptors in immature cells, leading to caspase-mediated GATA1 protein cleavage and differentiation arrest and apoptosis [82].

In a subsequent study by Ribeil et al., it was shown that caspase 3 was the predominant caspase activated in the nucleus of terminally differentiating erythroid cells which can cleave GATA1, for example, when starving erythroid precursors for Epo, resulting in cell death by apoptosis [83]. Furthermore, Ribeil et al. uncovered a mechanism that protects GATA1 from cleavage by caspase 3 activation in the nucleus during human erythroid cell maturation. Specifically, they showed that Epo mediated erythroblast survival and 
terminal differentiation results in the nuclear translocation of the HSP70 protein chaperone and its specific interaction with GATA1 protein, thus protecting it from cleavage by activated caspase 3 [83]. Under conditions of Epo starvation, HSP70 translocates out of the nucleus and no longer protects GATA1 which now becomes cleaved by caspase 3 , thus leading to differentiation arrest and apoptosis [83]. Thus, HSP70 protects GATA1 from programmed caspase 3 activation in the Epo-dependent, early stages of erythroid cell maturation as a cell survival and differentiation protective mechanism, whereas at later stages, Epo-independent mature erythroid cells can signal death receptor and caspase activation in immature cells, leading to GATA1 cleavage and differentiation arrest as a homeostatic control mechanism. It is unclear whether this mechanism also operates in the murine system, as murine GATA1 protein does not share the caspase cleavage site with human GATA1 [82]. Interestingly, a recent study further added to the GATA1/HSP70 protective axis by showing that nuclear HSP70 and GATA1 protein levels were modulated by the p19iNK4d cyclin-dependent kinase inhibitor [109]. Specifically, it was shown that p19INK4d downregulated PEBP1 (phosphatidylethanolamine-binding protein 1), resulting in stabilized nuclear HSP70 protein levels through increased ERK phosphorylation, known to be implicated in HSP70 nuclear localization [109]. Importantly, the GATA1/HSP70 protective mechanism breaks down in hematological disorders presenting with ineffective erythropoiesis, as outlined below.

A recent study uncovered an additional caspase-mediated mechanism for regulating GATA1 protein levels in hematopoiesis [110]. Inflammasome activation in HSCs due to infection, led to caspase 1 activation and GATA1 cleavage and degradation, thus biasing cell fate decisions towards the myeloid lineage. Inhibition of caspase 1 in murine HSCs resulted in the upregulation of GATA1 protein and an increase in megakaryocyticerythroid (MegE) colony output at the expense of granulocyte-monocyte (GM) colonies, suggesting an evolutionarily conserved mechanism for the inflammasome regulating hematopoietic cell fate decisions by fine-tuning GATA1. In addition, the same study showed that the cleavage of GATA1 by caspase 1 was required for the final steps of hemin-induced erythroid differentiation in K562 cells, thus pointing at an additional mechanism whereby the inflammasome could regulate erythropoiesis through GATA1. Importantly, just like for caspase 3, GATA1 was indeed shown to be a substrate for cleavage by caspase 1 in vitro [110].

The role of the proteasome in erythropoiesis has been highlighted through the years, and it is well known that proteasome-inhibitor drugs used as anti-tumoral agents, 
especially in multiple myeloma, may cause anemia as an adverse event [111-113]. However, perhaps counterintuitively, chemical inhibition of the proteasome in murine erythroid progenitors, or loss of the proteasome shuttle protein Rad23b, results in reduced levels of GATA1 leading to early apoptosis in vitro and to anemia in vivo, respectively [114]. A better understanding of the action of the proteasome in erythropoiesis and how it may regulate directly or indirectly GATA1 levels, is currently the research focus of several groups $[112,113,115,116]$.

\section{The effects of artificially altering GATA1 protein levels}

As outlined above, GATA1 translation and protein levels are exquisitely regulated in hematopoiesis and it is now well established that tinkering with GATA1 protein levels has important functional implications and may also result in hematological disease. For example, the extremes of either a complete loss of GATA1 expression or GATA1 overexpression, result in both cases in embryonic lethal anemia [22,117]. Another study using inducible GATA1 expression in an immortalized GATA1-null proerythroblastic cell line, demonstrated differential sensitivity of target genes to the dosage of GATA1 protein [118]. Studies using transgenic mice under- or over-expressing GATA1 have been particularly useful in investigating the effects of altering GATA1 protein levels in hematopoiesis. Specifically, two GATA1 knockdown mouse models have been generated by the Yamamoto and Orkin groups expressing GATA1 at $5 \%$ or $20 \%$ of its physiological levels, respectively $[119,120]$. The first mouse model, called GATA1.05, was generated by the insertion of a neomycin resistance cassette in the GATA1 promoter region, which resulted in GATA1 expression at $5 \%$ its physiological level [119]. Hemizygous male GATA1.05 embryos die from severe anemia between E11.5 and E12.5, suggesting that $5 \%$ GATA1 expression is not sufficient to support primitive erythropoiesis. Interestingly, using in vitro differentiated ES cells, it was shown that both GATA1.05 and GATA1-null cells resulted in reduced expression of p16 INK4A and accelerated cell cycle progression, however, $5 \%$ of GATA1 expression was sufficient to maintain expression of the anti-apoptotic $B c l-X_{L}$ gene, thus protecting the cells from apoptotic cell death normally observed with GATA1-null cells [121]. These results provide further evidence for subtle alterations in GATA1 expression levels having differential effects on the expression of GATA1 target genes.

In contrast to male mice, heterozygous GATA1.05 female mice were born at slightly lower than expected Mendelian frequencies and often developed perinatally varying degrees of transient anemia (due to $X$ inactivation), from which they recovered [119, 121]. However, between 3 and 6 months of age, GATA1.05 female mice frequently 
develop erythroleukemia, characterized by the proliferation of immature erythroid progenitors [122]. By contrast, heterozygous GATA1-null female mice do not present with erythroleukemia. The difference between the two conditions (which only differ by $5 \%$ in the expression of GATA 1 ), may lie in the observation that $5 \%$ of GATA 1 is sufficient to protect cells from apoptosis, but not from uncontrollable cell proliferation [121]. By contrast, GATA1-null cells in a heterozygous female background would be eliminated by apoptosis. Thus, additional genetic events that may occur in the proliferating GATA1.05 progenitor population can lead to leukemic transformation [122-124]. Interestingly, older GATA1.05 mice also develop CD19+ B-cell leukemia through a leukemogenic mechanism that is not yet understood, but may be related to lineage commitment skewing towards lymphoid fates by proliferating progenitors expressing low levels of GATA1 [122].

The second GATA1 knockdown mouse strain was generated by replacing an upstream enhancer region in the GATA1 gene locus with a neomycin resistance cassette [120]. In these mice, known as GATA1 low mice, GATA1 expression levels were originally reported to be knocked down to $20 \%$ [120], although subsequent analyses have shown GATA1 mRNA reduced by as much as 100-fold in orthochromatic erythroblasts ([125] and references therein). The majority of GATA1low male mice die of anemia between embryonic stages E13.5 and E14.5. In contrast to the GATA1.05 mice, a few GATA1 low male mice are born alive but are severely anemic, but for some of them anemia resolves around 4-5 weeks of age [120]. These observations suggest that $\sim 20 \%$ GATA1 expression is insufficient to support primitive erythropoiesis but sufficient for adult erythropoiesis. Interestingly, GATA1 expression in the megakaryocytes of GATA1low mice is completely abolished and the mice are born with severe thrombocytopenia, associated with the expansion of abnormal megakaryocytic progenitors that, at 10 months of age, develops into a myeloproliferative condition characterized by fibrosis of the bone marrow, closely resembling primary myelofibrosis $[125,126]$. GATA1 ${ }^{\text {low }}$ mice also have defects in mast cell differentiation, as evidenced by the amplification of mast cell progenitors, increased apoptotic precursors and defective differentiation of mature cells [127]. These observations provide yet more evidence for the necessity of maintaining appropriate GATA1 levels to support balanced hematopoiesis.

GATA1 overexpression has also been shown to have dramatic effects in erythropoiesis in vivo. In particular, a mouse model was generated bearing an X-linked GATA1 transgene driven by the Locus Control Region (LCR) of the human $\beta$-globin locus (the GATA1-OX transgene), resulting in the overexpression of GATA1 beyond the 
proerythroblast stage, at the moment of maximum globin transcription [117]. Male embryos carrying the GATA1-OX transgene die in utero in mid gestation due to anemia, whereas heterozygous females survive to term and develop normally. From this study it was shown that GATA1 overexpression at the proerythroblast stage causes cell cycle arrest and apoptosis of erythroid progenitors beyond the proerythroblast stage. Intriguingly, in heterozygous females it was shown that GATA1-OX progenitors were able to mature at an almost normal rate [117]. The explanation for this phenomenon lies in the erythroblastic island, i.e. the histological unit where erythropoiesis takes place in the bone marrow $[128,129]$. The erythroblastic island is composed of a central macrophage surrounded by erythroid progenitors in successive stages of differentiation, emanating from the center towards the periphery of the island. It is in this periphery where mature erythroblasts will enucleate and the expelled pyrenocyte will be phagocytosed by the central macrophage [130]. In this hierarchical histological unit, erythroid cells are in contact and communicate with each other, thus providing an internal feedback mechanism measuring differentiation rate and assuring maturation and production of red blood cells in response to physiological demands at any given moment [131, 132]. Due to X-chromosome inactivation, the erythroblastic islands of heterozygous GATA1-OX females are chimeric in composition, i.e. approximately $50 \%$ of erythroid progenitors overexpress GATA1 (the $X$ chromosome carrying the GATA1-OX transgene is active), and $50 \%$ of erythroid progenitors express GATA1 at normal levels (the wildtype $X$ chromosome is active). Based on this, it was proposed that maturing erythroid cells in later stages of differentiation induce the terminal differentiation of earlier progenitors through cell-cell signaling mechanisms, which result in the downregulation of GATA1 protein levels as a necessary regulatory cadency for proper erythroid terminal maturation [117]. This provides a mechanism to ensure a smooth production of red blood cells in wild type mice. However, in the heterozygous GATA1-OX females, this results in the "rescue" of the GATA1 overexpressing cells, which are able to differentiate when in close proximity to wildtype maturing erythroid cells, which provide a signal directed towards the downregulation of GATA1 protein levels. This signal was tentatively named "REDS" (red cell differentiation signal). A follow-up study using mice with different combinations of the GATA1-OX transgene and a GATA1-knockout allele, provided further evidence for REDS signaling by wildtype maturing erythroid cells: when crossed with GATA1 knockout mice, heterozygous GATA1-OX females died in mid gestation due to anemia (similar to GATA1-OX males) [133]. However, to-date, the identity of the REDS receptor/ligand is not known. Regulation of GATA1 transcription at the terminal differentiation stages and recent work suggesting that REDS might act to regulate GATA1 levels through the inhibition of translation (L. Gutiérrez, manuscript in 
preparation), are possibilities. Overall, the REDS signal serves as another example of homeostatic regulation of erythropoiesis through GATA1 protein level regulation.

Lastly, it should be noted that artificially altering GATA1 expression levels through its enforced expression in hematopoietic progenitors, can push them to cell fates towards lineages that are normally regulated by GATA1 [134, 135]. For example, ectopic expression of GATA1 in avian myeloid progenitors [136] or in human primary myeloid progenitors [137] reprogrammed them to erythroid and megakaryocytic or eosinophilic cell fates, respectively. These studies support the notion that different thresholds of GATA1 expression levels in hematopoietic progenitors, can govern cell fate decisions towards different lineages.

\section{Downregulation of GATA1 protein levels and ineffective erythropoiesis}

Ineffective erythropoiesis (IE) or dyserythropoiesis is a pathological feature shared by a number of hematological diseases such as $\beta$ thalassemia, myelodysplastic syndromes (MDS), Diamond-Blackfan anemia (DBA), 5q-syndrome and myelofibrosis [138]. IE is characterized by the abnormal differentiation of erythroid progenitors resulting in an expanded progenitor compartment, increased destruction of abnormal erythroblasts and a paucity in the production of mature erythroid cells. Recent work has shown that the downregulation of GATA1 protein levels is a critical aspect of IE in hematological disease. Three mechanisms have been described to account for reduced GATA1 protein levels in IE: (i) inherited GATA1 mutations greatly reducing, or eliminating altogether, expression of the full length GATA1 protein [139, 140]; (ii) impaired translation of full length GATA1 [80, 84], and (iii) impaired HSP70-mediated protection of GATA1 protein from cleavage and degradation [141].

The best example of inherited GATA1 mutations in IE is that of Diamond-Blackfan Anemia (DBA). This is an inherited bone marrow failure syndrome characterized by anemia, macrocytosis, reticulopenia and selective reduction or absence of erythroid precursors (BFU-Es) in an otherwise normocellular bone marrow [142]. More than 200 heterozygous mutations in 19 ribosomal protein (RP) genes have been recorded to-date, accounting for most (approximately $70 \%$ ), but not all, of the DBA cases [143, 144]. Sankaran and colleagues were the first to identify through exome sequencing a GATA1 mutation associated with DBA [145]. This mutation was a c.220G $>C$ transversion that caused the skipping of exon 2, resulting in the loss of full length GATA1 protein, with the continued expression of the GATA1s isoform. Additional cases in DBA with similar GATA1 mutations have been reported $[84,146,147]$, including a mutation that resulted 
in the loss of the first translation initiation codon responsible for the production of full length GATA1 protein, again without affecting GATA1s expression [84, 147]. These findings are significant in explaining dyserythropoiesis in these patients, as it has been shown that the GATA1s isoform cannot fully support erythropoiesis [20, 21, 148]. Furthermore, these results show that the mutations in the GATA1 gene that give rise to reduced, or absent, full length GATA1 protein, in the absence of RP gene mutations, are sufficient to cause disease. In addition, Hollanda et al. reported a family with a similar $\mathrm{G}$ $>\mathrm{C}$ transition at the boundary of exon 2 in the GATA1 gene in male members, which also resulted in the exclusive expression of GATA1s giving rise to macrocytic anemia and variable neutropenia, with no apparent thrombocytopenia [149]. The differences in disease manifestation between the two reports of the $\mathrm{G}>\mathrm{C}$ mutation in exon 2 of the GATA1 gene remain unclear, but it has been suggested that they may be due to differences in the levels of total GATA1 protein expressed [145]. Lastly, Sankaran and colleagues recently identified two patients with dyserythropoietic anemia and thrombocytopenia, due to a mutation that affects canonical splicing of the GATA1 mRNA [150]. Specifically, a single nucleotide change was identified 24 nucleotides upstream of the canonical splice site in intron 5 of the GATA1 gene. This mutation results in an increase in the use of the mutated site as an alternative splice acceptor site, with a reduction in canonical splicing. This leads to a partial intron retention event that introduces an extra 5 amino acids C-terminally to the C-terminal zinc finger of GATA1, with a concomitant reduction in the expression of wild-type GATA1 to $\sim 40 \%$ its normal levels. Importantly, the mutant GATA1 protein was functionally inactive as it could not rescue erythroid differentiation in functional complementation assays in the GATA1-null G1E murine proerythroblastic cell line [150].

The analysis of the molecular basis of DBA, again provided important clues as to the implication of reduced GATA1 protein levels in IE in hematological disease. As outlined above, DBA is primarily associated with heterozygous mutations in a number of RP genes. It is now known that deficiencies in RPs act upstream of GATA1 in downregulating its protein translation levels, whilst mRNA levels remain unaffected [84]. In accordance with this, knocking down RPS19 expression, or that of other RP genes, led to a significant reduction in GATA1 protein levels resulting in deficient erythropoiesis, reminiscent of DBA [84]. As described above, it appears that the particular sensitivity of the GATA1 mRNA to RP levels is mediated by the particular sequence and structure of its 5' UTR, as it was shown that the presence of the 5' UTR is critical for GATA1 erythroid function [80]. Interestingly, mutations in the RPS14 gene were also found in patients with primary myelofibrosis and were again associated with reduced GATA1 protein levels and 
impaired megakaryopoiesis [151], thus linking RP gene mutations and reduced GATA1 protein levels in hematological disease affecting a hematopoietic lineage other than the erythroid lineage. Furthermore, it was recently shown that heme levels are retroactively involved in this spectrum of phenomena around ribosomal protein dependent GATA1 protein level regulation [152]. This study showed that in early erythroid progenitors, heme induces the translation of ribosomal proteins, ensuring sustained globin synthesis. However, at later stages of differentiation, heme accumulation associates with downregulation of Gata1 through an still undescribed mechanism [152].

As described above, GATA1 protein is normally protected from caspase-mediated cleavage in the early stages of erythroid differentiation, through its interaction in the nucleus with the HSP70 protein chaperone [83]. This GATA1 protective mechanism appears to break down in hematological disorders manifesting with IE, such as DBA and myelodysplastic syndromes (MDS). In DBA, it was recently shown that HSP70 protein is downregulated due to its increased ubiquitination and proteasomal degradation in RPL11- and RPL5-deficient human primary erythroid cells, but not in RPS19-deficient cells, resulting in proliferation and differentiation defects and increased apoptosis in erythroid cells, resembling DBA features [153]. A subsequent study showed a disequilibrium of globin chain and heme synthesis in RPL11- and RPL5-deficient human erythroid cells, resulting in excessive free heme which downregulated HSP70 protein [154]. The study by Doty et al. also suggests that aberrant accumulation of heme, contributes to the amplification of ribosomal protein imbalance, thus causing premature downregulation of GATA1 levels, responsible for the IE that is characteristic of DBA and MDS [152]. Hence, it is clear in that in DBA, HSP70 downregulation results in a significant drop in GATA1 protein levels due to caspase mediated cleavage, which underlies the observed erythroid maturation defects [153]. The HSP70 mediated protection of GATA1 is also disrupted in $\beta$-thalassemia, which also manifests with IE. Here, it was shown in primary human $\beta$-thalassemic erythroblasts that free $\alpha$-globin chains sequester HSP70 to the cytoplasm, resulting in significant downregulation of nuclear GATA1 protein and a blockade in terminal erythroid differentiation [155]. Lastly, myelodysplastic syndromes are clonal disorders also characterized by IE associated with defective erythroid maturation and increased apoptosis of erythroid precursors [138]. Here too, it was shown that nuclear GATA1 protein was significantly lower as a result of aberrant HSP70 localization in the cytoplasm, accounting for the blockade in erythroid differentiation in MDS [141]. Thus, downregulation or absence of full length GATA1 protein in erythroid precursors, either directly through mutations in the GATA1 gene itself, or indirectly through defects in GATA1 mRNA translation or the breakdown of the HSP70/GATA1 
protective axis, result in defective erythropoiesis and disease. This is an addition to hematological deficiencies or malignancies affecting other hematopoietic lineages, where downregulation or loss of the full length GATA1 protein play a causative role, for example, in primary myelofibrosis affecting the megakaryocytic lineage [125] or in trisomy 21 associated transient myeloproliferative disorder (TMD), acute megakaryoblastic leukemia (AMKL) and clonal eosinophilia [156, 157].

Interestingly enough, a balanced erythropoietic production is disturbed in the presence of subjacent inflammation, a phenomenon that has been named as anemia of inflammation or anemia of chronic disease. The most frequent scenario occurs when the body feels a need to increase white blood cell (WBC) production in response to infection, at the expense of red blood cell (RBC) production; in this case, the anemia is caused by a rise in IL-6 and hepcidin levels, with subsequent inhibition of iron absorption, ultimately resulting in reduced erythropoiesis [158]. It has been shown that inflammatory molecules themselves (i.e. TNFa, IL6, IFN $\gamma$ ) are able to promote lymphoid production at the expense of the erythroid compartment, either skewing lineage specification, or even targeting directly GATA1 levels in erythroid progenitors [159-161]. It has been shown that the proinflammatory cytokine TNF $\alpha$, induces an erythroid defect in K562 cells in vitro. The molecular mechanism implies downregulation of both GATA1 mRNA and protein levels and decreased GATA1 DNA binding capacity. The study by Buck et al identifies GATA2-dependent transcriptional deregulation of GATA1, proteasomedependent degradation of GATA1, and altered post-translational modification of GATA1 (acetylation) as a consequence of TNF $\alpha$ treatment [161]. Curiously, another study showed that, in vitro, hematopoietic precursors bearing mutations in RPS19 (accounting for $25 \%$ of mutations associated with DBA), present with deficient erythropoiesis which is accompanied by overproduction of TNF $\alpha$ by co-cultured non-erythroid cells. Addition of the TNF $\alpha$ inhibitor Etarnecept overcomes partially the erythroid defect [158]. Bibikova et al apply this therapeutic strategy on an experimental zebrafish morphant model deficient for rps19, which phenocopies the dyserythropoiesis and TNF $\alpha$ increase of DBA, and are able to rescue partially the erythropoietic defect by inhibiting TNF $\alpha$ [159]. In a transgenic mouse model of anemia of chronic disease, characterized by enhanced CD27-mediated costimulation and a strong increase in the formation of IFN $\gamma$-producing effector T cells, progressive anemia is due to inhibition of erythropoiesis through the IRF1-dependent activation of PU.1 transcription factor in hematopoietic precursors [159]. This exemplifies how the hematopoietic production balance is self-regulated through transcriptional reprogramming of hematopoietic precursors, GATA1 being a main 
physiological target the levels of which fine-tune erythroid production in health and in disease through natural mechanisms that could be used to develop novel and efficient therapeutic strategies in well-known erythroid-related disorders.

\section{Conclusions}

The fine-tuning of GATA1 protein levels has emerged as a key mechanism for regulating erythropoiesis. High GATA1 protein levels are required in the EPO-dependent early stages of erythropoiesis in providing cell survival functions, in addition to activating the erythroid transcription program. Adequate GATA1 protein levels in the early stages of erythroid differentiation are ensured by the efficient translation of GATA1 mRNA and its protection from cleavage by activated caspase 3 through GATA1's interaction with the HSP70 protein chaperone. Subsequently, GATA1 needs to be drastically downregulated for the terminal stage of erythroid maturation to take place, in a homeostatic mechanism that balances the production of red blood cells depending on surplus or demand. GATA1 protein levels also affect cell fate decisions, as evidenced by the reprogramming of myeloid progenitors towards MegE fates by GATA1 overexpression. Furthermore, inflammasomes appear to exploit the caspase-mediated cleavage of GATA1 in HSCs in order to tip the balance towards enhanced myeloid differentiation in response to infection. Lastly, the combined action of GATA1 post-translational modifications has been proposed as a mechanism to control the active, chromatin-bound fraction of GATA1 by targeting it for proteasomal degradation as a mechanism for regulating GATA1 transcriptional activity in response to signals (Figure 2). It has also become clear that, in addition to genetic mutations affecting GATA1, defects in the different levels of regulatory checkpoints for physiological GATA1 expression also play a key role in the physiopathology of disease hematological diseases associated with inefficient erythropoiesis. With the advent of novel, unbiased, single cell-based technologies, we stand to gain a much better understanding of GATA1 regulatory mechanisms and the cascading effects of their deregulation in vertebrate hematopoiesis and in human disease. Newly gained knowledge will help the development of novel therapies targeting the restoration of GATA1 regulation in treating inefficient erythropoiesis and anemia in hematological disease in man.

\section{Acknowledgments}


We apologize to the many of our colleagues whose work we were not able to cite due to space restrictions. L.G. is supported by a Ramón y Cajal Fellowship (RYC-2013-12587; Ministerio de Economía y Competitividad, Spain). E.K. is supported by a Scholarship for Strengthening Post-Doctoral Research from the Greek State Scholarships Foundation (IKY), within the framework of the Operational Program "Human Resources Development program, Education and Life-Long learning". We are thankful to Dr. Martijn Nolte and Dr. Sten Libregts (Sanquin Research, Amsterdam, the Netherlands) for performing the experiments and providing the data for the intracellular GATA1 staining in murine bone marrow, performed as a previous joint collaboration with L.G. 


\section{References}

1. Adam, R. C., Yang, H., Rockowitz, S., Larsen, S. B., Nikolova, M., Oristian, D. S., Polak, L., Kadaja, M., Asare, A., Zheng, D. \& Fuchs, E. (2015) Pioneer factors govern super-enhancer dynamics in stem cell plasticity and lineage choice, Nature. 521, 366-70.

2. Brown, G., Ceredig, R. \& Tsapogas, P. (2018) The Making of Hematopoiesis: Developmental Ancestry and Environmental Nurture, Int $\mathrm{J} \mathrm{Mol} \mathrm{Sci.} 19$.

3. Jacobsen, S. E. W. \& Nerlov, C. (2019) Haematopoiesis in the era of advanced single-cell technologies, Nat Cell Biol. 21, 2-8.

4. Hofer, T. \& Rodewald, H. R. (2018) Differentiation-based model of hematopoietic stem cell functions and lineage pathways, Blood. 132, 1106-1113.

5. Dzierzak, E. \& Philipsen, S. (2013) Erythropoiesis: development and differentiation, Cold Spring Harb Perspect Med. 3, a011601.

6. Liang, R. \& Ghaffari, S. (2016) Advances in understanding the mechanisms of erythropoiesis in homeostasis and disease, Br J Haematol. 174, 661-73.

7. Palis, J. (2014) Primitive and definitive erythropoiesis in mammals, Front Physiol. 5, 3.

8. Kerenyi, M. A. \& Orkin, S. H. (2010) Networking erythropoiesis, J Exp Med. 207, 2537-41.

9. Ferreira, R., Ohneda, K., Yamamoto, M. \& Philipsen, S. (2005) GATA1 function, a paradigm for transcription factors in hematopoiesis, Mol Cell Biol. 25, 1215-27.

10. Tremblay, M., Sanchez-Ferras, O. \& Bouchard, M. (2018) GATA transcription factors in development and disease, Development. 145.

11. Lowry, J. A. \& Atchley, W. R. (2000) Molecular evolution of the GATA family of transcription factors: conservation within the DNA-binding domain, J Mol Evol. 50, 103-15.

12. Weiss, M. J. \& Orkin, S. H. (1995) GATA transcription factors: key regulators of hematopoiesis, Exp Hematol. 23, 99-107.

13. Katsumura, K. R., Bresnick, E. H. \& Group, G. F. M. (2017) The GATA factor revolution in hematology, Blood. 129, 2092-2102.

14. Ko, L. J. \& Engel, J. D. (1993) DNA-binding specificities of the GATA transcription factor family, Mol Cell Biol. 13, 4011-22.

15. Vyas, P., Ault, K., Jackson, C. W., Orkin, S. H. \& Shivdasani, R. A. (1999) Consequences of GATA-1 deficiency in megakaryocytes and platelets, Blood. 93, 2867-75.

16. Yu, C., Cantor, A. B., Yang, H., Browne, C., Wells, R. A., Fujiwara, Y. \& Orkin, S. H. (2002) Targeted deletion of a high-affinity GATA-binding site in the GATA-1 promoter leads to selective loss of the eosinophil lineage in vivo, J Exp Med. 195, 1387-95.

17. Nei, Y., Obata-Ninomiya, K., Tsutsui, H., Ishiwata, K., Miyasaka, M., Matsumoto, K., Nakae, S., Kanuka, H., Inase, N. \& Karasuyama, H. (2013) GATA-1 regulates the generation and function of basophils, Proc Natl Acad Sci U S A. 110, 18620-5.

18. Gutierrez, L., Nikolic, T., van Dijk, T. B., Hammad, H., Vos, N., Willart, M., Grosveld, F., Philipsen, S. \& Lambrecht, B. N. (2007) Gata1 regulates dendritic-cell development and survival, Blood. 110, 1933-41.

19. Sasaki, H., Kurotaki, D. \& Tamura, T. (2016) Regulation of basophil and mast cell development by transcription factors, Allergol Int. 65, 127-134.

20. Byrska-Bishop, M., VanDorn, D., Campbell, A. E., Betensky, M., Arca, P. R., Yao, Y., Gadue, P., Costa, F. F., Nemiroff, R. L., Blobel, G. A., French, D. L., Hardison, R. C., Weiss, M. J. \& Chou, S. T. (2015) Pluripotent stem cells reveal erythroid-specific activities of the GATA1 Nterminus, J Clin Invest. 125, 993-1005.

21. Ling, T., Birger, Y., Stankiewicz, M. J., Ben-Haim, N., Kalisky, T., Rein, A., Kugler, E., Chen, W., Fu, C., Zhang, K., Patel, H., Sikora, J. W., Goo, Y. A., Kelleher, N., Zou, L., Izraeli, S. \& Crispino, J. D. (2019) Chromatin occupancy and epigenetic analysis reveal new insights into the function of GATA1 N-terminus in erythropoiesis, Blood.

22. Pevny, L., Simon, M. C., Robertson, E., Klein, W. H., Tsai, S. F., D'Agati, V., Orkin, S. H. \& Costantini, F. (1991) Erythroid differentiation in chimaeric mice blocked by a targeted mutation in the gene for transcription factor GATA-1, Nature. 349, 257-60.

23. Pevny, L., Lin, C. S., D'Agati, V., Simon, M. C., Orkin, S. H. \& Costantini, F. (1995) Development of hematopoietic cells lacking transcription factor GATA-1, Development. 121, 163-72.

24. Weiss, M. J. \& Orkin, S. H. (1995) Transcription factor GATA-1 permits survival and maturation of erythroid precursors by preventing apoptosis, Proc Natl Acad Sci U S A. 92, 9623-7. 
25. Gutierrez, L., Tsukamoto, S., Suzuki, M., Yamamoto-Mukai, H., Yamamoto, M., Philipsen, S. \& Ohneda, K. (2008) Ablation of Gata1 in adult mice results in aplastic crisis, revealing its essential role in steady-state and stress erythropoiesis, Blood. 111, 4375-85.

26. Cheng, Y., Wu, W., Kumar, S. A., Yu, D., Deng, W., Tripic, T., King, D. C., Chen, K. B., Zhang, Y., Drautz, D., Giardine, B., Schuster, S. C., Miller, W., Chiaromonte, F., Zhang, Y., Blobel, G. A., Weiss, M. J. \& Hardison, R. C. (2009) Erythroid GATA1 function revealed by genomewide analysis of transcription factor occupancy, histone modifications, and mRNA expression, Genome Res. 19, 2172-84.

27. Fujiwara, T., O'Geen, H., Keles, S., Blahnik, K., Linnemann, A. K., Kang, Y. A., Choi, K., Farnham, P. J. \& Bresnick, E. H. (2009) Discovering hematopoietic mechanisms through genome-wide analysis of GATA factor chromatin occupancy, Mol Cell. 36, 667-81.

28. Yu, M., Riva, L., Xie, H., Schindler, Y., Moran, T. B., Cheng, Y., Yu, D., Hardison, R., Weiss, M. J., Orkin, S. H., Bernstein, B. E., Fraenkel, E. \& Cantor, A. B. (2009) Insights into GATA1-mediated gene activation versus repression via genome-wide chromatin occupancy analysis, Mol Cell. 36, 682-95.

29. Papadopoulos, G. L., Karkoulia, E., Tsamardinos, I., Porcher, C., Ragoussis, J., Bungert, J. \& Strouboulis, J. (2013) GATA-1 genome-wide occupancy associates with distinct epigenetic profiles in mouse fetal liver erythropoiesis, Nucleic Acids Res. 41, 4938-48.

30. Kang, Y. A., Sanalkumar, R., O'Geen, H., Linnemann, A. K., Chang, C. J., Bouhassira, E. E., Farnham, P. J., Keles, S. \& Bresnick, E. H. (2012) Autophagy driven by a master regulator of hematopoiesis, Mol Cell Biol. 32, 226-39.

31. Mclver, S. C., Kang, Y. A., DeVilbiss, A. W., O'Driscoll, C. A., Ouellette, J. N., Pope, N. J., Camprecios, G., Chang, C. J., Yang, D., Bouhassira, E. E., Ghaffari, S. \& Bresnick, E. H. (2014) The exosome complex establishes a barricade to erythroid maturation, Blood. 124, 2285-97.

32. Mclver, S. C., Katsumura, K. R., Davids, E., Liu, P., Kang, Y. A., Yang, D. \& Bresnick, E. H. (2016) Exosome complex orchestrates developmental signaling to balance proliferation and differentiation during erythropoiesis, Elife. 5.

33. Huang, D. Y., Kuo, Y. Y., Lai, J. S., Suzuki, Y., Sugano, S. \& Chang, Z. F. (2004) GATA-1 and NF-Y cooperate to mediate erythroid-specific transcription of Gfi-1B gene, Nucleic Acids Res. 32, 3935-46.

34. Vilaboa, N., Bermejo, R., Martinez, P., Bornstein, R. \& Cales, C. (2004) A novel E2 boxGATA element modulates Cdc6 transcription during human cells polyploidization, Nucleic Acids Res. 32, 6454-67.

35. Fernandez-Morales, B., Pavon, L. \& Cales, C. (2012) CDC6 expression is regulated by lineage-specific transcription factor GATA1, Cell Cycle. 11, 3055-66.

36. Papetti, M., Wontakal, S. N., Stopka, T. \& Skoultchi, A. I. (2010) GATA-1 directly regulates p21 gene expression during erythroid differentiation, Cell Cycle. 9, 1972-80.

37. Gregory, T., Yu, C., Ma, A., Orkin, S. H., Blobel, G. A. \& Weiss, M. J. (1999) GATA-1 and erythropoietin cooperate to promote erythroid cell survival by regulating bcl-xL expression, Blood. 94, 87-96.

38. Tanaka, H., Matsumura, I., Nakajima, K., Daino, H., Sonoyama, J., Yoshida, H., Oritani, K., Machii, T., Yamamoto, M., Hirano, T. \& Kanakura, Y. (2000) GATA-1 blocks IL-6-induced macrophage differentiation and apoptosis through the sustained expression of cyclin D1 and bcl-2 in a murine myeloid cell line M1, Blood. 95, 1264-73.

39. Chou, S. T., Khandros, E., Bailey, L. C., Nichols, K. E., Vakoc, C. R., Yao, Y., Huang, Z., Crispino, J. D., Hardison, R. C., Blobel, G. A. \& Weiss, M. J. (2009) Graded repression of PU.1/Sfpi1 gene transcription by GATA factors regulates hematopoietic cell fate, Blood. 114, 983-94.

40. Dore, L. C., Amigo, J. D., Dos Santos, C. O., Zhang, Z., Gai, X., Tobias, J. W., Yu, D., Klein, A. M., Dorman, C., Wu, W., Hardison, R. C., Paw, B. H. \& Weiss, M. J. (2008) A GATA-1regulated microRNA locus essential for erythropoiesis, Proc Natl Acad Sci U S A. 105, 33338.

41. Rasmussen, K. D., Simmini, S., Abreu-Goodger, C., Bartonicek, N., Di Giacomo, M., BilbaoCortes, D., Horos, R., Von Lindern, M., Enright, A. J. \& O'Carroll, D. (2010) The miR-144/451 locus is required for erythroid homeostasis, J Exp Med. 207, 1351-8.

42. Wang, F., Zhu, Y., Guo, L., Dong, L., Liu, H., Yin, H., Zhang, Z., Li, Y., Liu, C., Ma, Y., Song, W., He, A., Wang, Q., Wang, L., Zhang, J., Li, J. \& Yu, J. (2014) A regulatory circuit comprising GATA1/2 switch and microRNA-27a/24 promotes erythropoiesis, Nucleic Acids Res. 42, 44257. 
43. Kadauke, S., Udugama, M. I., Pawlicki, J. M., Achtman, J. C., Jain, D. P., Cheng, Y., Hardison, R. C. \& Blobel, G. A. (2012) Tissue-specific mitotic bookmarking by hematopoietic transcription factor GATA1, Cell. 150, 725-37.

44. Tsang, A. P., Visvader, J. E., Turner, C. A., Fujiwara, Y., Yu, C., Weiss, M. J., Crossley, M. \& Orkin, S. H. (1997) FOG, a multitype zinc finger protein, acts as a cofactor for transcription factor GATA-1 in erythroid and megakaryocytic differentiation, Cell. 90, 109-19.

45. Crispino, J. D., Lodish, M. B., MacKay, J. P. \& Orkin, S. H. (1999) Use of altered specificity mutants to probe a specific protein-protein interaction in differentiation: the GATA-1:FOG complex, Mol Cell. 3, 219-28.

46. Chang, A. N., Cantor, A. B., Fujiwara, Y., Lodish, M. B., Droho, S., Crispino, J. D. \& Orkin, S. H. (2002) GATA-factor dependence of the multitype zinc-finger protein FOG-1 for its essential role in megakaryopoiesis, Proc Natl Acad Sci U S A. 99, 9237-42.

47. Nichols, K. E., Crispino, J. D., Poncz, M., White, J. G., Orkin, S. H., Maris, J. M. \& Weiss, M. J. (2000) Familial dyserythropoietic anaemia and thrombocytopenia due to an inherited mutation in GATA1, Nat Genet. 24, 266-70.

48. Rodriguez, P., Bonte, E., Krijgsveld, J., Kolodziej, K. E., Guyot, B., Heck, A. J., Vyas, P., de Boer, E., Grosveld, F. \& Strouboulis, J. (2005) GATA-1 forms distinct activating and repressive complexes in erythroid cells, EMBO J. 24, 2354-66.

49. Hong, W., Nakazawa, M., Chen, Y. Y., Kori, R., Vakoc, C. R., Rakowski, C. \& Blobel, G. A. (2005) FOG-1 recruits the NuRD repressor complex to mediate transcriptional repression by GATA-1, EMBO J. 24, 2367-78.

50. Miccio, A., Wang, Y., Hong, W., Gregory, G. D., Wang, H., Yu, X., Choi, J. K., Shelat, S., Tong, W., Poncz, M. \& Blobel, G. A. (2010) NuRD mediates activating and repressive functions of GATA-1 and FOG-1 during blood development, EMBO J. 29, 442-56.

51. Wadman, I. A., Osada, H., Grutz, G. G., Agulnick, A. D., Westphal, H., Forster, A. \& Rabbitts, T. H. (1997) The LIM-only protein Lmo2 is a bridging molecule assembling an erythroid, DNAbinding complex which includes the TAL1, E47, GATA-1 and Ldb1/NLI proteins, EMBO J. 16, 3145-57.

52. Kassouf, M. T., Hughes, J. R., Taylor, S., McGowan, S. J., Soneji, S., Green, A. L., Vyas, P. \& Porcher, C. (2010) Genome-wide identification of TAL1's functional targets: insights into its mechanisms of action in primary erythroid cells, Genome Res. 20, 1064-83.

53. Soler, E., Andrieu-Soler, C., de Boer, E., Bryne, J. C., Thongjuea, S., Stadhouders, R., Palstra, R. J., Stevens, M., Kockx, C., van ljcken, W., Hou, J., Steinhoff, C., Rijkers, E., Lenhard, B. \& Grosveld, F. (2010) The genome-wide dynamics of the binding of Ldb1 complexes during erythroid differentiation, Genes Dev. 24, 277-89.

54. Jurata, L. W., Pfaff, S. L. \& Gill, G. N. (1998) The nuclear LIM domain interactor NLI mediates homo- and heterodimerization of LIM domain transcription factors, J Biol Chem. 273, 31527.

55. Love, P. E., Warzecha, C. \& Li, L. (2014) Ldb1 complexes: the new master regulators of erythroid gene transcription, Trends Genet. 30, 1-9.

56. Liu, G. \& Dean, A. (2019) Enhancer long-range contacts: The multi-adaptor protein LDB1 is the tie that binds, Biochim Biophys Acta Gene Regul Mech. 1862, 625-633.

57. Morceau, F., Schnekenburger, M., Dicato, M. \& Diederich, M. (2004) GATA-1: friends, brothers, and coworkers, Ann N Y Acad Sci. 1030, 537-54.

58. Kang, Y., Kim, Y. W., Yun, J., Shin, J. \& Kim, A. (2015) KLF1 stabilizes GATA-1 and TAL1 occupancy in the human beta-globin locus, Biochim Biophys Acta. 1849, 282-9.

59. Merika, M. \& Orkin, S. H. (1995) Functional synergy and physical interactions of the erythroid transcription factor GATA-1 with the Kruppel family proteins Sp1 and EKLF, Mol Cell Biol. 15, 2437-47.

60. Kuo, Y. Y. \& Chang, Z. F. (2007) GATA-1 and Gfi-1B interplay to regulate Bcl-xL transcription, Mol Cell Biol. 27, 4261-72.

61. Kadam, S. \& Emerson, B. M. (2003) Transcriptional specificity of human SWI/SNF BRG1 and BRM chromatin remodeling complexes, Mol Cell. 11, 377-89.

62. Kadri, Z., Shimizu, R., Ohneda, O., Maouche-Chretien, L., Gisselbrecht, S., Yamamoto, M., Romeo, P. H., Leboulch, P. \& Chretien, S. (2009) Direct binding of pRb/E2F-2 to GATA-1 regulates maturation and terminal cell division during erythropoiesis, PLoS Biol. 7, e1000123.

63. Blobel, G. A., Nakajima, T., Eckner, R., Montminy, M. \& Orkin, S. H. (1998) CREB-binding protein cooperates with transcription factor GATA-1 and is required for erythroid differentiation, Proc Natl Acad Sci U S A. 95, 2061-6. 
64. Hung, H. L., Lau, J., Kim, A. Y., Weiss, M. J. \& Blobel, G. A. (1999) CREB-Binding protein acetylates hematopoietic transcription factor GATA-1 at functionally important sites, Mol Cell Biol. 19, 3496-505.

65. Zon, L. I., Tsai, S. F., Burgess, S., Matsudaira, P., Bruns, G. A. \& Orkin, S. H. (1990) The major human erythroid DNA-binding protein (GF-1): primary sequence and localization of the gene to the $X$ chromosome, Proc Natl Acad Sci U S A. 87, 668-72.

66. Shimizu, R. \& Yamamoto, M. (2005) Gene expression regulation and domain function of hematopoietic GATA factors, Semin Cell Dev Biol. 16, 129-36.

67. McDevitt, M. A., Fujiwara, Y., Shivdasani, R. A. \& Orkin, S. H. (1997) An upstream, DNase I hypersensitive region of the hematopoietic-expressed transcription factor GATA-1 gene confers developmental specificity in transgenic mice, Proc Natl Acad Sci U S A. 94, 7976-81.

68. Valverde-Garduno, V., Guyot, B., Anguita, E., Hamlett, I., Porcher, C. \& Vyas, P. (2004) Differences in the chromatin structure and cis-element organization of the human and mouse GATA1 loci: implications for cis-element identification, Blood. 104, 3106-16.

69. Nishimura, S., Takahashi, S., Kuroha, T., Suwabe, N., Nagasawa, T., Trainor, C. \& Yamamoto, M. (2000) A GATA box in the GATA-1 gene hematopoietic enhancer is a critical element in the network of GATA factors and sites that regulate this gene, Mol Cell Biol. 20, 713-23.

70. Vyas, P., McDevitt, M. A., Cantor, A. B., Katz, S. G., Fujiwara, Y. \& Orkin, S. H. (1999) Different sequence requirements for expression in erythroid and megakaryocytic cells within a regulatory element upstream of the GATA-1 gene, Development. 126, 2799-811.

71. Guyot, B., Valverde-Garduno, V., Porcher, C. \& Vyas, P. (2004) Deletion of the major GATA1 enhancer HS 1 does not affect eosinophil GATA1 expression and eosinophil differentiation, Blood. 104, 89-91.

72. Yamamoto, M., Takahashi, S., Onodera, K., Muraosa, Y. \& Engel, J. D. (1997) Upstream and downstream of erythroid transcription factor GATA-1, Genes Cells. 2, 107-15.

73. Kobayashi, M. \& Yamamoto, M. (2007) Regulation of GATA1 gene expression, J Biochem. 142, 1-10.

74. Deindl, P., Klar, M., Drews, D., Cremer, M., Gammella, E., Gassmann, M. \& Dame, C. (2014) Mice over-expressing human erythropoietin indicate that erythropoietin enhances expression of its receptor via up-regulated Gata1 and Tal1, Haematologica. 99, e205-7.

75. Zhao, W., Kitidis, C., Fleming, M. D., Lodish, H. F. \& Ghaffari, S. (2006) Erythropoietin stimulates phosphorylation and activation of GATA-1 via the PI3-kinase/AKT signaling pathway, Blood. 107, 907-15.

76. Zon, L. I., Youssoufian, H., Mather, C., Lodish, H. F. \& Orkin, S. H. (1991) Activation of the erythropoietin receptor promoter by transcription factor GATA-1, Proc Natl Acad Sci U SA. 88, 10638-41.

77. Leonard, M., Brice, M., Engel, J. D. \& Papayannopoulou, T. (1993) Dynamics of GATA transcription factor expression during erythroid differentiation, Blood. 82, 1071-9.

78. Suzuki, N., Suwabe, N., Ohneda, O., Obara, N., Imagawa, S., Pan, X., Motohashi, H. \& Yamamoto, M. (2003) Identification and characterization of 2 types of erythroid progenitors that express GATA-1 at distinct levels, Blood. 102, 3575-83.

79. Gutierrez, L., Lindeboom, F., Ferreira, R., Drissen, R., Grosveld, F., Whyatt, D. \& Philipsen, S. (2005) A hanging drop culture method to study terminal erythroid differentiation, Exp Hematol. 33, 1083-91.

80. Khajuria, R. K., Munschauer, M., Ulirsch, J. C., Fiorini, C., Ludwig, L. S., McFarland, S. K., Abdulhay, N. J., Specht, H., Keshishian, H., Mani, D. R., Jovanovic, M., Ellis, S. R., Fulco, C. P., Engreitz, J. M., Schutz, S., Lian, J., Gripp, K. W., Weinberg, O. K., Pinkus, G. S., Gehrke, L., Regev, A., Lander, E. S., Gazda, H. T., Lee, W. Y., Panse, V. G., Carr, S. A. \& Sankaran, V. G. (2018) Ribosome Levels Selectively Regulate Translation and Lineage Commitment in Human Hematopoiesis, Cell. 173, 90-103 e19.

81. Palii, C. G., Cheng, Q., Gillespie, M. A., Shannon, P., Mazurczyk, M., Napolitani, G., Price, N. D., Ranish, J. A., Morrissey, E., Higgs, D. R. \& Brand, M. (2019) Single-Cell Proteomics Reveal that Quantitative Changes in Co-expressed Lineage-Specific Transcription Factors Determine Cell Fate, Cell Stem Cell. 24, 812-820 e5.

82. De Maria, R., Zeuner, A., Eramo, A., Domenichelli, C., Bonci, D., Grignani, F., Srinivasula, S. M., Alnemri, E. S., Testa, U. \& Peschle, C. (1999) Negative regulation of erythropoiesis by caspase-mediated cleavage of GATA-1, Nature. 401, 489-93.

83. Ribeil, J. A., Zermati, Y., Vandekerckhove, J., Cathelin, S., Kersual, J., Dussiot, M., Coulon, S., Moura, I. C., Zeuner, A., Kirkegaard-Sorensen, T., Varet, B., Solary, E., Garrido, C. \& 
Hermine, O. (2007) Hsp70 regulates erythropoiesis by preventing caspase-3-mediated cleavage of GATA-1, Nature. 445, 102-5.

84. Ludwig, L. S., Gazda, H. T., Eng, J. C., Eichhorn, S. W., Thiru, P., Ghazvinian, R., George, T. I., Gotlib, J. R., Beggs, A. H., Sieff, C. A., Lodish, H. F., Lander, E. S. \& Sankaran, V. G. (2014) Altered translation of GATA1 in Diamond-Blackfan anemia, Nat Med. 20, 748-53.

85. Crispino, J. D. (2005) GATA1 in normal and malignant hematopoiesis, Semin Cell Dev Biol. 16, 137-47.

86. Martin, D. I. \& Orkin, S. H. (1990) Transcriptional activation and DNA binding by the erythroid factor GF-1/NF-E1/Eryf 1, Genes Dev. 4, 1886-98.

87. Chennupati, V., Veiga, D. F., Maslowski, K. M., Andina, N., Tardivel, A., Yu, E. C., Stilinovic, M., Simillion, C., Duchosal, M. A., Quadroni, M., Roberts, I., Sankaran, V. G., MacDonald, H. R., Fasel, N., Angelillo-Scherrer, A., Schneider, P., Hoang, T. \& Allam, R. (2018) Ribonuclease inhibitor 1 regulates erythropoiesis by controlling GATA1 translation, J Clin Invest. 128, 1597-1614.

88. Chan, J., Hu, X., Wang, C. \& Xu, Q. (2018) miRNA-152 targets GATA1 to regulate erythropoiesis in Chionodraco hamatus, Biochem Biophys Res Commun. 501, 711-717.

89. Kim, M., Civin, C. I. \& Kingsbury, T. J. (2019) MicroRNAs as regulators and effectors of hematopoietic transcription factors, Wiley Interdiscip Rev RNA. 10, e1537.

90. Lessard, S., Beaudoin, M., Orkin, S. H., Bauer, D. E. \& Lettre, G. (2018) 14q32 and let-7 microRNAs regulate transcriptional networks in fetal and adult human erythroblasts, Hum Mol Genet. 27, 1411-1420.

91. Wang, F., Yu, J., Yang, G. H., Wang, X. S. \& Zhang, J. W. (2011) Regulation of erythroid differentiation by miR-376a and its targets, Cell Res. 21, 1196-209.

92. Crossley, M. \& Orkin, S. H. (1994) Phosphorylation of the erythroid transcription factor GATA1, J Biol Chem. 269, 16589-96.

93. Hernandez-Hernandez, A., Ray, P., Litos, G., Ciro, M., Ottolenghi, S., Beug, H. \& Boyes, J. (2006) Acetylation and MAPK phosphorylation cooperate to regulate the degradation of active GATA-1, EMBO J. 25, 3264-74.

94. Yu, Y. L., Chiang, Y. J., Chen, Y. C., Papetti, M., Juo, C. G., Skoultchi, A. I. \& Yen, J. J. (2005) MAPK-mediated phosphorylation of GATA-1 promotes Bcl-XL expression and cell survival, J Biol Chem. 280, 29533-42.

95. Partington, G. A. \& Patient, R. K. (1999) Phosphorylation of GATA-1 increases its DNAbinding affinity and is correlated with induction of human K562 erythroleukaemia cells, Nucleic Acids Res. 27, 1168-75.

96. Omichinski, J. G., Trainor, C., Evans, T., Gronenborn, A. M., Clore, G. M. \& Felsenfeld, G. (1993) A small single-"finger" peptide from the erythroid transcription factor GATA-1 binds specifically to DNA as a zinc or iron complex, Proc Natl Acad Sci U S A. 90, 1676-80.

97. Towatari, M., Ciro, M., Ottolenghi, S., Tsuzuki, S. \& Enver, T. (2004) Involvement of mitogenactivated protein kinase in the cytokine-regulated phosphorylation of transcription factor GATA-1, Hematol J. 5, 262-72.

98. Rooke, H. M. \& Orkin, S. H. (2006) Phosphorylation of Gata1 at serine residues 72, 142, and 310 is not essential for hematopoiesis in vivo, Blood. 107, 3527-30.

99. Boyes, J., Byfield, P., Nakatani, Y. \& Ogryzko, V. (1998) Regulation of activity of the transcription factor GATA-1 by acetylation, Nature. 396, 594-8.

100. Boyes, J., Omichinski, J., Clark, D., Pikaart, M. \& Felsenfeld, G. (1998) Perturbation of nucleosome structure by the erythroid transcription factor GATA-1, J Mol Biol. 279, 529-44.

101. Lamonica, J. M., Vakoc, C. R. \& Blobel, G. A. (2006) Acetylation of GATA-1 is required for chromatin occupancy, Blood. 108, 3736-8.

102. Lamonica, J. M., Deng, W., Kadauke, S., Campbell, A. E., Gamsjaeger, R., Wang, H., Cheng, Y., Billin, A. N., Hardison, R. C., Mackay, J. P. \& Blobel, G. A. (2011) Bromodomain protein Brd3 associates with acetylated GATA1 to promote its chromatin occupancy at erythroid target genes, Proc Natl Acad Sci U S A. 108, E159-68.

103. de Thonel, A., Vandekerckhove, J., Lanneau, D., Selvakumar, S., Courtois, G., Hazoume, A., Brunet, M., Maurel, S., Hammann, A., Ribeil, J. A., Zermati, Y., Gabet, A. S., Boyes, J., Solary, E., Hermine, O. \& Garrido, C. (2010) HSP27 controls GATA-1 protein level during erythroid cell differentiation, Blood. 116, 85-96.

104. Lin, K. R., Li, C. L., Yen, J. J. \& Yang-Yen, H. F. (2013) Constitutive phosphorylation of GATA-1 at serine(2)(6) attenuates the colony-forming activity of erythrocyte-committed progenitors, PLoS One. 8, e64269. 
105. Liang, L., Peng, Y., Zhang, J., Zhang, Y., Roy, M., Han, X., Xiao, X., Sun, S., Liu, H., Nie, L., Kuang, Y., Zhu, Z., Deng, J., Xia, Y., Sankaran, V. G., Hillyer, C. D., Mohandas, N., Ye, M., An, X. \& Liu, J. (2019) Deubiquitylase USP7 regulates human terminal erythroid differentiation by stabilizing GATA1, Haematologica.

106. Collavin, L., Gostissa, M., Avolio, F., Secco, P., Ronchi, A., Santoro, C. \& Del Sal, G. (2004) Modification of the erythroid transcription factor GATA-1 by SUMO-1, Proc Natl Acad Sci U S A. 101, 8870-5.

107. Lee, H. Y., Johnson, K. D., Fujiwara, T., Boyer, M. E., Kim, S. I. \& Bresnick, E. H. (2009) Controlling hematopoiesis through sumoylation-dependent regulation of a GATA factor, Mol Cell. 36, 984-95.

108. Yu, L., Ji, W., Zhang, H., Renda, M. J., He, Y., Lin, S., Cheng, E. C., Chen, H., Krause, D. S. \& Min, W. (2010) SENP1-mediated GATA1 deSUMOylation is critical for definitive erythropoiesis, J Exp Med. 207, 1183-95.

109. Han, X., Zhang, J., Peng, Y., Peng, M., Chen, X., Chen, H., Song, J., Hu, X., Ye, M., Li, J., Sankaran, V. G., Hillyer, C. D., Mohandas, N., An, X. \& Liu, J. (2017) Unexpected role for p19INK4d in posttranscriptional regulation of GATA1 and modulation of human terminal erythropoiesis, Blood. 129, 226-237.

110. Tyrkalska, S. D., Perez-Oliva, A. B., Rodriguez-Ruiz, L., Martinez-Morcillo, F. J., AlcarazPerez, F., Martinez-Navarro, F. J., Lachaud, C., Ahmed, N., Schroeder, T., Pardo-Sanchez, I., Candel, S., Lopez-Munoz, A., Choudhuri, A., Rossmann, M. P., Zon, L. I., Cayuela, M. L., Garcia-Moreno, D. \& Mulero, V. (2019) Inflammasome Regulates Hematopoiesis through Cleavage of the Master Erythroid Transcription Factor GATA1, Immunity. 51, 50-63 e5.

111. Richardson, P. G., Sonneveld, P., Schuster, M. W., Irwin, D., Stadtmauer, E. A., Facon, T., Harousseau, J. L., Ben-Yehuda, D., Lonial, S., Goldschmidt, H., Reece, D., San-Miguel, J. F., Blade, J., Boccadoro, M., Cavenagh, J., Dalton, W. S., Boral, A. L., Esseltine, D. L., Porter, J. B., Schenkein, D., Anderson, K. C. \& Assessment of Proteasome Inhibition for Extending Remissions, I. (2005) Bortezomib or high-dose dexamethasone for relapsed multiple myeloma, N Engl J Med. 352, 2487-98.

112. Khandros, E., Thom, C. S., D'Souza, J. \& Weiss, M. J. (2012) Integrated protein qualitycontrol pathways regulate free alpha-globin in murine beta-thalassemia, Blood. 119, 526575.

113. Nguyen, A. T., Prado, M. A., Schmidt, P. J., Sendamarai, A. K., Wilson-Grady, J. T., Min, M., Campagna, D. R., Tian, G., Shi, Y., Dederer, V., Kawan, M., Kuehnle, N., Paulo, J. A., Yao, Y., Weiss, M. J., Justice, M. J., Gygi, S. P., Fleming, M. D. \& Finley, D. (2017) UBE2O remodels the proteome during terminal erythroid differentiation, Science. 357.

114. Bergink, S., Theil, A. F., Toussaint, W., De Cuyper, I. M., Kulu, D. I., Clapes, T., van der Linden, R., Demmers, J. A., Mul, E. P., van Alphen, F. P., Marteijn, J. A., van Gent, T., Maas, A., Robin, C., Philipsen, S., Vermeulen, W., Mitchell, J. R. \& Gutierrez, L. (2013) Erythropoietic defect associated with reduced cell proliferation in mice lacking the $26 \mathrm{~S}$ proteasome shuttling factor Rad23b, Mol Cell Biol. 33, 3879-92.

115. Khandros, E. \& Weiss, M. J. (2010) Protein quality control during erythropoiesis and hemoglobin synthesis, Hematol Oncol Clin North Am. 24, 1071-88.

116. Thom, C. S., Traxler, E. A., Khandros, E., Nickas, J. M., Zhou, O. Y., Lazarus, J. E., Silva, A. P., Prabhu, D., Yao, Y., Aribeana, C., Fuchs, S. Y., Mackay, J. P., Holzbaur, E. L. \& Weiss, M. J. (2014) Trim58 degrades Dynein and regulates terminal erythropoiesis, Dev Cell. 30, 688-700.

117. Whyatt, D., Lindeboom, F., Karis, A., Ferreira, R., Milot, E., Hendriks, R., de Bruijn, M., Langeveld, A., Gribnau, J., Grosveld, F. \& Philipsen, S. (2000) An intrinsic but cellnonautonomous defect in GATA-1-overexpressing mouse erythroid cells, Nature. 406, 51924.

118. Johnson, K. D., Kim, S. I. \& Bresnick, E. H. (2006) Differential sensitivities of transcription factor target genes underlie cell type-specific gene expression profiles, Proc Natl Acad Sci $U$ $S$ A. 103, 15939-44.

119. Takahashi, S., Onodera, K., Motohashi, H., Suwabe, N., Hayashi, N., Yanai, N., Nabesima, Y. \& Yamamoto, M. (1997) Arrest in primitive erythroid cell development caused by promoterspecific disruption of the GATA-1 gene, J Biol Chem. 272, 12611-5.

120. McDevitt, M. A., Shivdasani, R. A., Fujiwara, Y., Yang, H. \& Orkin, S. H. (1997) A "knockdown" mutation created by cis-element gene targeting reveals the dependence of erythroid cell maturation on the level of transcription factor GATA-1, Proc Natl Acad Sci U S A. 94, 6781-5. 
121. Pan, X., Ohneda, O., Ohneda, K., Lindeboom, F., Iwata, F., Shimizu, R., Nagano, M., Suwabe, N., Philipsen, S., Lim, K. C., Engel, J. D. \& Yamamoto, M. (2005) Graded levels of GATA-1 expression modulate survival, proliferation, and differentiation of erythroid progenitors, J Biol Chem. 280, 22385-94.

122. Shimizu, R., Kuroha, T., Ohneda, O., Pan, X., Ohneda, K., Takahashi, S., Philipsen, S. \& Yamamoto, M. (2004) Leukemogenesis caused by incapacitated GATA-1 function, Mol Cell Biol. 24, 10814-25.

123. Shimizu, R. \& Yamamoto, M. (2012) Contribution of GATA1 dysfunction to multi-step leukemogenesis, Cancer Sci. 103, 2039-44.

124. Shimizu, R., Engel, J. D. \& Yamamoto, M. (2008) GATA1-related leukaemias, Nat Rev Cancer. 8, 279-87.

125. Ling, T., Crispino, J. D., Zingariello, M., Martelli, F. \& Migliaccio, A. R. (2018) GATA1 insufficiencies in primary myelofibrosis and other hematopoietic disorders: consequences for therapy, Expert Rev Hematol. 11, 169-184.

126. Vannucchi, A. M., Bianchi, L., Cellai, C., Paoletti, F., Rana, R. A., Lorenzini, R., Migliaccio, G. \& Migliaccio, A. R. (2002) Development of myelofibrosis in mice genetically impaired for GATA-1 expression (GATA-1(low) mice), Blood. 100, 1123-32.

127. Migliaccio, A. R., Rana, R. A., Sanchez, M., Lorenzini, R., Centurione, L., Bianchi, L., Vannucchi, A. M., Migliaccio, G. \& Orkin, S. H. (2003) GATA-1 as a regulator of mast cell differentiation revealed by the phenotype of the GATA-1low mouse mutant, J Exp Med. 197, 281-96.

128. Socolovsky, M. (2013) Exploring the erythroblastic island, Nat Med. 19, 399-401.

129. Yeo, J. H., Lam, Y. W. \& Fraser, S. T. (2019) Cellular dynamics of mammalian red blood cell production in the erythroblastic island niche, Biophys Rev.

130. McGrath, K. E., Kingsley, P. D., Koniski, A. D., Porter, R. L., Bushnell, T. P. \& Palis, J. (2008) Enucleation of primitive erythroid cells generates a transient population of "pyrenocytes" in the mammalian fetus, Blood. 111, 2409-17.

131. Mohandas, N. \& Chasis, J. A. (2010) The erythroid niche: molecular processes occurring within erythroblastic islands, Transfus Clin Biol. 17, 110-1.

132. Chasis, J. A. \& Mohandas, N. (2008) Erythroblastic islands: niches for erythropoiesis, Blood. 112, 470-8.

133. Gutierrez, L., Lindeboom, F., Langeveld, A., Grosveld, F., Philipsen, S. \& Whyatt, D. (2004) Homotypic signalling regulates Gata1 activity in the erythroblastic island, Development. 131, 3183-93.

134. Graf, T. (2002) Differentiation plasticity of hematopoietic cells, Blood. 99, 3089-101.

135. Iwasaki, H., Mizuno, S., Wells, R. A., Cantor, A. B., Watanabe, S. \& Akashi, K. (2003) GATA1 converts lymphoid and myelomonocytic progenitors into the megakaryocyte/erythrocyte lineages, Immunity. 19, 451-62.

136. Kulessa, H., Frampton, J. \& Graf, T. (1995) GATA-1 reprograms avian myelomonocytic cell lines into eosinophils, thromboblasts, and erythroblasts, Genes Dev. 9, 1250-62.

137. Hirasawa, R., Shimizu, R., Takahashi, S., Osawa, M., Takayanagi, S., Kato, Y., Onodera, M., Minegishi, N., Yamamoto, M., Fukao, K., Taniguchi, H., Nakauchi, H. \& Iwama, A. (2002) Essential and instructive roles of GATA factors in eosinophil development, J Exp Med. 195, 1379-86.

138. Valent, P., Busche, G., Theurl, I., Uras, I. Z., Germing, U., Stauder, R., Sotlar, K., Fureder, W., Bettelheim, P., Pfeilstocker, M., Oberbauer, R., Sperr, W. R., Geissler, K., Schwaller, J., Moriggl, R., Bene, M. C., Jager, U., Horny, H. P. \& Hermine, O. (2018) Normal and pathological erythropoiesis in adults: from gene regulation to targeted treatment concepts, Haematologica. 103, 1593-1603.

139. Barbarani, G., Fugazza, C., Strouboulis, J. \& Ronchi, A. E. (2019) The Pleiotropic Effects of GATA1 and KLF1 in Physiological Erythropoiesis and in Dyserythropoietic Disorders, Front Physiol. 10, 91.

140. Crispino, J. D. \& Horwitz, M. S. (2017) GATA factor mutations in hematologic disease, Blood. 129, 2103-2110.

141. Frisan, E., Vandekerckhove, J., de Thonel, A., Pierre-Eugene, C., Sternberg, A., Arlet, J. B., Floquet, C., Gyan, E., Kosmider, O., Dreyfus, F., Gabet, A. S., Courtois, G., Vyas, P., Ribeil, J. A., Zermati, Y., Lacombe, C., Mayeux, P., Solary, E., Garrido, C., Hermine, O. \& Fontenay, M. (2012) Defective nuclear localization of $\mathrm{Hsp} 70$ is associated with dyserythropoiesis and GATA-1 cleavage in myelodysplastic syndromes, Blood. 119, 15321542. 
142. Ellis, S. R. \& Lipton, J. M. (2008) Diamond Blackfan anemia: a disorder of red blood cell development, Curr Top Dev Biol. 82, 217-41.

143. Ulirsch, J. C., Verboon, J. M., Kazerounian, S., Guo, M. H., Yuan, D., Ludwig, L. S., Handsaker, R. E., Abdulhay, N. J., Fiorini, C., Genovese, G., Lim, E. T., Cheng, A., Cummings, B. B., Chao, K. R., Beggs, A. H., Genetti, C. A., Sieff, C. A., Newburger, P. E., Niewiadomska, E., Matysiak, M., Vlachos, A., Lipton, J. M., Atsidaftos, E., Glader, B., Narla, A., Gleizes, P. E., O'Donohue, M. F., Montel-Lehry, N., Amor, D. J., McCarroll, S. A., O'Donnell-Luria, A. H., Gupta, N., Gabriel, S. B., MacArthur, D. G., Lander, E. S., Lek, M., Da Costa, L., Nathan, D. G., Korostelev, A. A., Do, R., Sankaran, V. G. \& Gazda, H. T. (2018) The Genetic Landscape of Diamond-Blackfan Anemia, Am J Hum Genet. 103, 930-947.

144. Boria, I., Garelli, E., Gazda, H. T., Aspesi, A., Quarello, P., Pavesi, E., Ferrante, D., Meerpohl, J. J., Kartal, M., Da Costa, L., Proust, A., Leblanc, T., Simansour, M., Dahl, N., Frojmark, A. S., Pospisilova, D., Cmejla, R., Beggs, A. H., Sheen, M. R., Landowski, M., Buros, C. M., Clinton, C. M., Dobson, L. J., Vlachos, A., Atsidaftos, E., Lipton, J. M., Ellis, S. R., Ramenghi, U. \& Dianzani, I. (2010) The ribosomal basis of Diamond-Blackfan Anemia: mutation and database update, Hum Mutat. 31, 1269-79.

145. Sankaran, V. G., Ghazvinian, R., Do, R., Thiru, P., Vergilio, J. A., Beggs, A. H., Sieff, C. A., Orkin, S. H., Nathan, D. G., Lander, E. S. \& Gazda, H. T. (2012) Exome sequencing identifies GATA1 mutations resulting in Diamond-Blackfan anemia, J Clin Invest. 122, 2439-43.

146. Klar, J., Khalfallah, A., Arzoo, P. S., Gazda, H. T. \& Dahl, N. (2014) Recurrent GATA1 mutations in Diamond-Blackfan anaemia, Br J Haematol. 166, 949-51.

147. Parrella, S., Aspesi, A., Quarello, P., Garelli, E., Pavesi, E., Carando, A., Nardi, M., Ellis, S. R., Ramenghi, U. \& Dianzani, I. (2014) Loss of GATA-1 full length as a cause of DiamondBlackfan anemia phenotype, Pediatr Blood Cancer. 61, 1319-21.

148. Chlon, T. M., McNulty, M., Goldenson, B., Rosinski, A. \& Crispino, J. D. (2015) Global transcriptome and chromatin occupancy analysis reveal the short isoform of GATA1 is deficient for erythroid specification and gene expression, Haematologica. 100, 575-84.

149. Hollanda, L. M., Lima, C. S., Cunha, A. F., Albuquerque, D. M., Vassallo, J., Ozelo, M. C., Joazeiro, P. P., Saad, S. T. \& Costa, F. F. (2006) An inherited mutation leading to production of only the short isoform of GATA-1 is associated with impaired erythropoiesis, Nat Genet. 38, $807-12$.

150. Abdulhay, N. J., Fiorini, C., Verboon, J. M., Ludwig, L. S., Ulirsch, J. C., Zieger, B., Lareau, C. A., Mi, X., Roy, A., Obeng, E. A., Erlacher, M., Gupta, N., Gabriel, S. B., Ebert, B. L., Niemeyer, C. M., Khoriaty, R. N., Ancliff, P., Gazda, H. T., Wlodarski, M. W. \& Sankaran, V. G. (2019) Impaired human hematopoiesis due to a cryptic intronic GATA1 splicing mutation, J Exp Med. 216, 1050-1060.

151. Gilles, L., Arslan, A. D., Marinaccio, C., Wen, Q. J., Arya, P., McNulty, M., Yang, Q., Zhao, J. C., Konstantinoff, K., Lasho, T., Pardanani, A., Stein, B., Plo, I., Sundaravel, S., Wickrema, A., Migliaccio, A., Gurbuxani, S., Vainchenker, W., Platanias, L. C., Tefferi, A. \& Crispino, J. D. (2017) Downregulation of GATA1 drives impaired hematopoiesis in primary myelofibrosis, J Clin Invest. 127, 1316-1320.

152. Doty, R. T., Yan, X., Lausted, C., Munday, A. D., Yang, Z., Yi, D., Jabbari, N., Liu, L., Keel, S. B., Tian, Q. \& Abkowitz, J. L. (2019) Single-cell analyses demonstrate that a heme-GATA1 feedback loop regulates red cell differentiation, Blood. 133, 457-469.

153. Gastou, M., Rio, S., Dussiot, M., Karboul, N., Moniz, H., Leblanc, T., Sevin, M., Gonin, P., Larghero, J., Garrido, C., Narla, A., Mohandas, N., Vainchenker, W., Hermine, O., Solary, E., Da Costa, L., French Society of, H., French Society of, I. \& Hematology (2017) The severe phenotype of Diamond-Blackfan anemia is modulated by heat shock protein 70, Blood Adv. 1, 1959-1976.

154. Rio, S., Gastou, M., Karboul, N., Derman, R., Suriyun, T., Manceau, H., Leblanc, T., El Benna, J., Schmitt, C., Azouzi, S., Larghero, J., Karim, Z., Macias-Garcia, A., Chen, J. J., Hermine, O., Courtois, G., Puy, H., Gouya, L., Mohandas, N. \& Da Costa, L. (2019) Regulation of globin-heme balance in Diamond-Blackfan anemia by HSP70/GATA1, Blood. 133, 1358-1370.

155. Arlet, J. B., Ribeil, J. A., Guillem, F., Negre, O., Hazoume, A., Marcion, G., Beuzard, Y., Dussiot, M., Moura, I. C., Demarest, S., de Beauchene, I. C., Belaid-Choucair, Z., Sevin, M., Maciel, T. T., Auclair, C., Leboulch, P., Chretien, S., Tchertanov, L., Baudin-Creuza, V., Seigneuric, R., Fontenay, M., Garrido, C., Hermine, O. \& Courtois, G. (2014) HSP70 sequestration by free alpha-globin promotes ineffective erythropoiesis in beta-thalassaemia, Nature. 514, 242-6. 
156. Bhatnagar, N., Nizery, L., Tunstall, O., Vyas, P. \& Roberts, I. (2016) Transient Abnormal Myelopoiesis and AML in Down Syndrome: an Update, Curr Hematol Malig Rep. 11, 333-41. 157. Maroz, A., Stachorski, L., Emmrich, S., Reinhardt, K., Xu, J., Shao, Z., Kabler, S., Dertmann, T., Hitzler, J., Roberts, I., Vyas, P., Juban, G., Hennig, C., Hansen, G., Li, Z., Orkin, S., Reinhardt, D. \& Klusmann, J. H. (2014) GATA1s induces hyperproliferation of eosinophil precursors in Down syndrome transient leukemia, Leukemia. 28, 1259-70.

158. Bibikova, E., Youn, M. Y., Danilova, N., Ono-Uruga, Y., Konto-Ghiorghi, Y., Ochoa, R., Narla, A., Glader, B., Lin, S. \& Sakamoto, K. M. (2014) TNF-mediated inflammation represses GATA1 and activates p38 MAP kinase in RPS19-deficient hematopoietic progenitors, Blood. 124, 3791-8.

159. Libregts, S. F., Gutierrez, L., de Bruin, A. M., Wensveen, F. M., Papadopoulos, P., van ljcken, W., Ozgur, Z., Philipsen, S. \& Nolte, M. A. (2011) Chronic IFN-gamma production in mice induces anemia by reducing erythrocyte life span and inhibiting erythropoiesis through an IRF-1/PU.1 axis, Blood. 118, 2578-88. 


\section{Figure Legends:}

\section{Figure 1: GATA1 protein levels during murine erythroid differentiation}

Intracellular flow cytometry analysis of GATA1 protein expression in mouse fetal and adult tissues. In brief, one million cells were stained with Ter119-PE antibody (fetal tissues) or a cocktail of KIT-PECy7/CD71-APC/Ter119-PE (adult tissues), and subsequently fixed and permeabilized using BD Cytofix/Cytoperm kit (BD Biosciences), after which they were incubated with anti-GATA1-N6 antibody (1:100) followed by antirat-FITC antibody (1:100) with a wash step after each incubation.

A) GATA1 protein levels were assessed using intracellular flow cytometry in murine fetal liver and fetal blood at E13.5. Representative data shown. In the top row, dot plots are depicted representing GATA1 expression level (MFI) against the Forward Scatter in fetal liver and fetal blood samples of the same mouse. In the mid row, dot plots are depicted of GATA1 levels (MFI) against Ter119 surface expression, including the Forward Scatter variable as a Heatmap Statistic colorcode in fetal liver and fetal blood samples of the same mouse. The plots on the right depict the overlay of respective fetal liver (red) and fetal blood (blue) samples on both rows. The bottom row is a composite figure, where representative pictures from cytospins of erythroid differentiating cells in vitro in hanging drop assays [79] and fetal blood nucleated and enucleated erythroid cells [133], are overlayed on the mid-row plots, as an indication of how differentiation takes place, with the remark that these cells do not correspond to prospectively isolated cells from the same samples. On the bottom right, a grapg depicting GATA1 expression levels (GeoMFI) in succesive stages of differentiation in fetal liver samples from 9 mice, based on Forward Scatter and Ter119 expression. "Enuc" means enucleated.

B) GATA1 protein levels were assessed using intracellular flow cytometry in murine bone marrow cells (data provided by Dr. Martijn Nolte). On the left, dot plots are depicted representing GATA1 expression level (MFI) against the Forward Scatter (top), and against Ter119 surface expression, including the Forward Scatter variable as a Heatmap 
Statistic colorcode (bottom). The graph represents GATA1 expression levels (GeoMFI) in successive stages of erythroid maturation based on surface marker expression, in 5 mice. The populations are from immature to mature, as follows: $\mathrm{KIT}^{+} \mathrm{CD} 71-\mathrm{Ter} 119^{-}$ (which includes other hematopoietic progenitors than erythroid), $\mathrm{KIT}^{+} \mathrm{CD} 71^{+}$Ter119-, KIT$\mathrm{CD}_{1}{ }^{+}$Ter119+ ${ }^{+}$and KIT-CD71-Ter119+. The picture of maturing erythroid cells, is a composite of differentiating cells in hanging drop assays in vitro [79], and is used to exemplify how erythroid differentiation takes place, from left to right, following the order of gated populations in the bone marrow.

Figure 2: Model of GATA1 protein level regulation during erythroid maturation Summary of the different mechanisms regulating GATA1 protein abundance, which lead to disease when deregulated. 
A
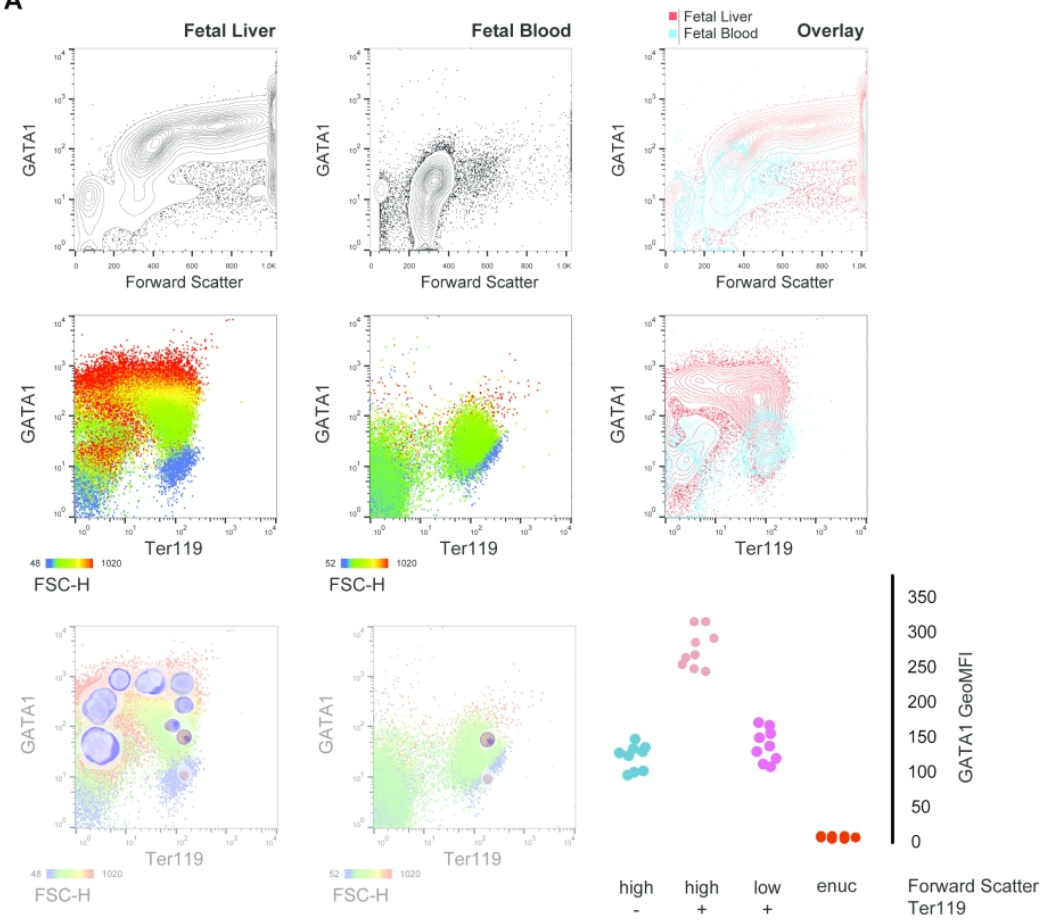

B
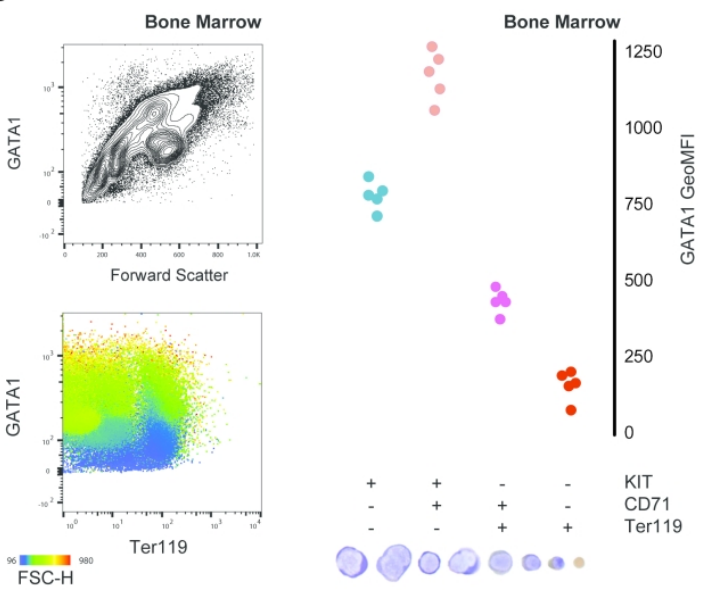

0000000

GATA1 protein levels during murine erythroid differentiation $198 \times 299 \mathrm{~mm}(300 \times 300 \mathrm{DPI})$ 


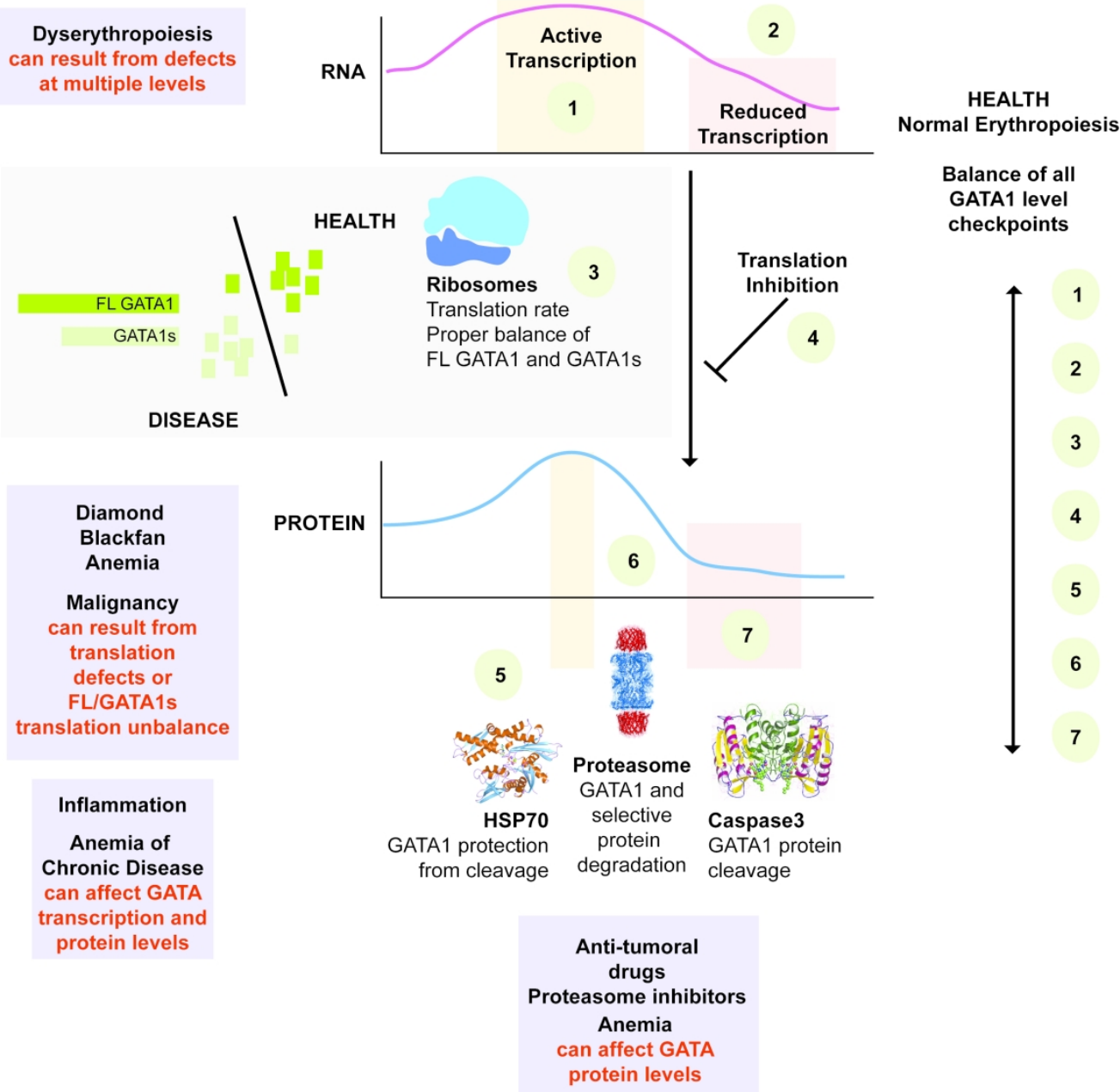

Model of GATA1 protein level regulation during erythroid maturation

$228 \times 241 \mathrm{~mm}(300 \times 300 \mathrm{DPI})$ 